\title{
The CO oxidation kinetics on supported Pd model catalysts: A molecular beam/in situ time-resolved infrared reflection absorption spectroscopy study
}

Cite as: J. Chem. Phys. 114, 4669 (2001); https://doi.org/10.1063/1.1342240

Submitted: 08 August 2000 . Accepted: 29 November 2000 . Published Online: 01 March 2001

J. Libuda, I. Meusel, J. Hoffmann, J. Hartmann, L. Piccolo, C. R. Henry, and H.-J. Freund

ARTICLES YOU MAY BE INTERESTED IN

A molecular beam investigation of the catalytic oxidation of CO on Pd (111)

The Journal of Chemical Physics 69, 1267 (1978); https://doi.org/10.1063/1.436666

Dependence of effective desorption kinetic parameters on surface coverage and adsorption temperature: CO on $\mathrm{Pd}(111)$

The Journal of Chemical Physics 90, 6761 (1989); https://doi.org/10.1063/1.456294

Transient and steady state CO oxidation kinetics on nanolithographically prepared supported Pd model catalysts: Experiments and simulations

The Journal of Chemical Physics 123, 054701 (2005); https://doi.org/10.1063/1.1949167

\section{Lock-in Amplifiers up to $600 \mathrm{MHz}$}
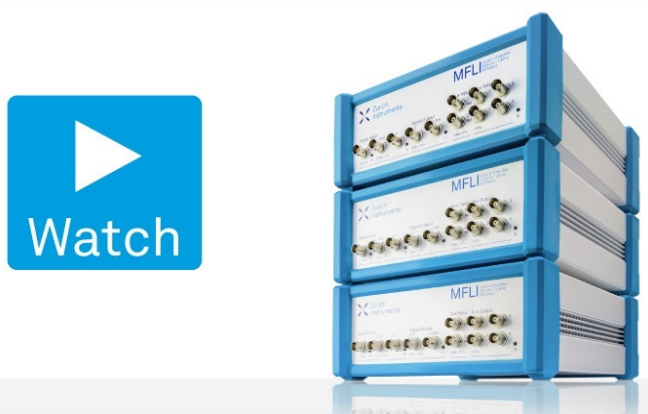

J. Chem. Phys. 114, 4669 (2001); https://doi.org/10.1063/1.1342240 


\title{
The CO oxidation kinetics on supported Pd model catalysts: A molecular beam/in situ time-resolved infrared reflection absorption spectroscopy study
}

\author{
J. Libuda, ${ }^{\text {a) }}$ I. Meusel, J. Hoffmann, and J. Hartmann \\ Fritz-Haber-Institut der Max-Planck-Gesellschaft, Faradayweg 4-6, D-14195 Berlin, Germany \\ L. Piccolob) and C. R. Henry \\ CRMC2-CNRS, Campus de Luminy, Case 913, F-13288 Marseille Cedex 9, France \\ H.-J. Freund \\ Fritz-Haber-Institut der Max-Planck-Gesellschaft, Faradayweg 4-6, D-14195 Berlin, Germany and CRMC2- \\ CNRS, Campus de Luminy, Case 913, F-13288 Marseille Cedex 9, France
}

(Received 8 August 2000; accepted 29 November 2000)

\begin{abstract}
Combining molecular beam techniques and time-resolved infrared reflection absorption spectroscopy (TR-IRAS) we have studied the kinetics of the $\mathrm{CO}$ oxidation reaction on an alumina-supported Pd model catalyst. The Pd particles are deposited by metal evaporation under ultrahigh vacuum (UHV) conditions onto a well-ordered alumina film, prepared on a $\mathrm{NiAl}(110)$ single crystal. Particle size, density and structure of the Pd deposits have been characterized in previous studies. In the low temperature region, transient and steady-state experiments have been performed over a wide range of $\mathrm{CO}$ and oxygen fluxes by crossing two effusive molecular beams on the sample surface. We determine the steady-state $\mathrm{CO}_{2}$ production rate as a function of the $\mathrm{CO}$ fraction in the impinging gas flux. Simultaneously, the occupation of $\mathrm{CO}$ adsorption sites under steady-state conditions is monitored by in situ IR spectroscopy. The origin of different types of $\mathrm{CO}_{2}$ transients is discussed. In particular we focus on the transient $\mathrm{CO}_{2}$ production after switching off the $\mathrm{CO}$ beam. For the model catalyst investigated, detailed reaction rate measurements in combination with time-resolved IRAS show that the origin of the particular transient behavior of the supported model system is not due to the presence of specific adsorption sites on small particles, as has been proposed previously. Instead, we show that the transient behavior can be semiquantitatively simulated on the basis of a simple kinetic model considering a homogeneous surface, and accounting for the inhibition of the dissociative adsorption of $\mathrm{O}_{2}$ at high $\mathrm{CO}$ coverage. Moreover, it is discussed how the inherent heterogeneity of the supported particle system can additionally enhance the observed effect. (C) 2001 American Institute of Physics. [DOI: 10.1063/1.1342240]
\end{abstract}

\section{INTRODUCTION}

What is the molecular origin of the kinetics of heterogeneously catalyzed reactions on supported metal systems being in many cases drastically different from the corresponding single crystal surfaces? As possible answers to this fundamental question in catalysis a number of concepts have been proposed. Among these are size effects, which may alter the electronic properties of small metal particles ${ }^{1,2}$ and thus the adsorption properties, geometrical effects due to the presence of specific adsorption sites or the combination of adsorption sites (see, e.g., Refs. 3-7), the influence of boundary sites at the metal oxide interface, ${ }^{8}$ metal support interactions, ${ }^{9-11}$ or support effects involving spillover from/to or reaction on the support (see, e.g., Refs. 4, 12, 13, and references therein). Recently, Zhdanov and Kasemo have pointed out that there might be a substantial influence

\footnotetext{
a) Author to whom correspondence should be addressed. Electronic mail: libuda@fhi-berlin.mpg.de; Fax: +49-30-8413-4309.

${ }^{b}$ Present address: DSM/DRECAM/SPCSI, CEA Saclay, F-91191 Gif-surYvette Cedex, France.
}

on the kinetics due to the coupling between nonequivalent adsorption sites by diffusion. ${ }^{5-7}$ The presence of such nonequivalent sites such as different facets, edge, defect or particle boundary sites is an inherent property of complex catalysts which cannot be modeled in studies on simple single crystal surfaces.

In spite of the numerous concepts, specific examples are scarce where there is clear experimental evidence concerning the origin of the effects mentioned before. The reasons for this lack of detailed knowledge is connected to what is usually referred to as the "materials gap" between surface science and catalysis (see, e.g., Refs. 14, 15). Real catalysts are usually hardly accessible by surface science methods. Moreover, their vast complexity may preclude an assignment of kinetic effects to specific molecular features of the system. On the other hand, the mentioned effects may not be present on simple single crystals, but only on such complex surfaces.

As a possible solution to this materials problem, a variety of supported model catalysts have been developed. These models allow us to introduce certain aspects of a real catalyst in a well controlled fashion, while still maintaining the experimental accessibility. Supported model catalysts have 


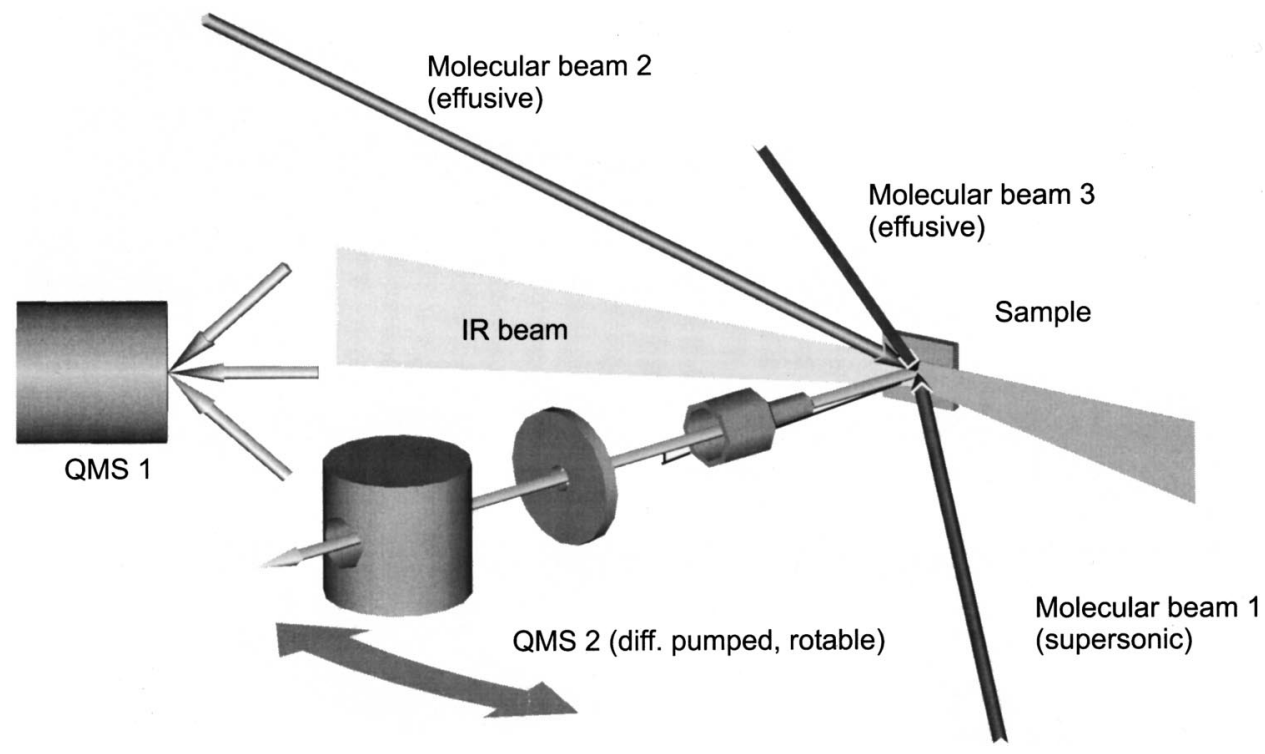

FIG. 1. Schematic representation of the molecular beam/IR spectroscopy experiment. been prepared based on both, oxide single crystal surfaces (see Ref. 4 and references therein) and thin ordered oxide films. ${ }^{15-19}$ Here, we will employ a $\mathrm{Pd} / \mathrm{Al}_{2} \mathrm{O}_{3}$ model system based on a thin well-ordered alumina film prepared on $\mathrm{NiAl}(110)$. The structure and defect structure of the oxide film ${ }^{20,21}$ as well as the growth, geometric structure, and electronic structure and the adsorption of Pd particles and other metals supported on this film have been extensively addressed in a series of previous studies. ${ }^{15-17,19,22-24}$

Once the structural properties of the supported model catalyst are well characterized, the next step is to establish a correlation between the structure and the microscopic kinetics. Here, molecular beam techniques represent the method of choice, ${ }^{25-28}$ providing a maximum of control over the reactant flux and its interaction with the sample. Ertl and Engel $^{29,30}$ have early applied beam methods to study the kinetics of the $\mathrm{CO}$ adsorption and oxidation and on $\operatorname{Pd}(111)$. In this study, they were able to demonstrate that the reaction follows a Langmuir-Hinshelwood (LH) mechanism and they succeeded to determine the LH activation barriers in various coverage regions. A variety of similar studies on other single crystal surfaces have been published since (see, e.g., Refs. 31-33). The previous work on supported model systems has been reviewed recently, and will not be discussed here in detail. ${ }^{4,22}$ It has to be pointed out, however, that, in spite of the successful experiments on single crystals, beam studies on the $\mathrm{CO}$ oxidation on supported catalysts are extremely rare. This is mainly due to the experimental problems mentioned before. As a consequence it remains unclear, to what extent size effects might be present on the system. ${ }^{4}$ Among the few examples for beam studies on supported model catalysts, Stará et al. have studied the transient $\mathrm{CO}_{2}$ production on $\mathrm{Pd} / \mathrm{Al}_{2} \mathrm{O}_{3}$ as a function of particle size and substrate structure, ${ }^{34,35}$ and found indications for significant size effects. No indications for a similar effect could be found in a recent study using the same model system as employed in this work. ${ }^{36}$ Becker and Henry have investigated, by molecular beam methods, the $\mathrm{CO}$ oxidation reaction on $\mathrm{Pd} / \mathrm{MgO}$ (100) model catalysts. ${ }^{37,38}$ Variations in the steady state pro- duction of $\mathrm{CO}_{2}$ with particle size were observed. However, these differences in activity were mainly due to the effect of the capture, by the Pd particles, of the CO physisorbed on the support (reverse-spillover) which is equivalent to an increase of the effective pressure on the particles when their size decreases (see Sec. III H) ${ }^{38}$ In addition, the transient behavior upon switching off the $\mathrm{CO}$ beam was considered in this work. A characteristic peak was found, the intensity of which increased with decreasing cluster size (for the same experimental conditions). The origin of this peak was attributed to low coordinated (edge and defect) sites, present on the supported particles. As has been proposed previously, ${ }^{3}$ those sites may bind $\mathrm{CO}$ more strongly and thus they may give rise to a pronounced transient $\mathrm{CO}_{2}$ production peak due to the increased residence time for $\mathrm{CO}$ at these sites.

In this study, we apply an experimental approach combining molecular beam techniques and TR-IRAS. We present a detailed study of the $\mathrm{CO}$ oxidation on well-shaped alumina supported Pd crystallites under steady-state and transient conditions. It is shown that the transient $\mathrm{CO}_{2}$ peak, which is also found for the present model system, is not related to specific adsorption sites. Instead we discuss two points: First, we will show that the transient kinetics of the $\mathrm{CO}$ oxidation reaction-including the behavior of the $\mathrm{CO}_{2}$ peak under discussion - can be qualitatively simulated from a simple "mean-field" kinetic model based on the data available on $\operatorname{Pd}(111)$. Secondly, we will argue, how the inherent heterogeneity of a supported catalyst may additionally enhance the observed effect.

\section{EXPERIMENT}

All experiments were performed in a new UHV molecular beam/surface spectroscopy apparatus at the Fritz-HaberInstitute (Berlin), which has been described in the literature, recently. ${ }^{39}$ Schematically, the setup is displayed in Fig. 1.

The system has been specifically designed for kinetic studies on complex model systems. It offers the experimental possibility of up to three beams being crossed on the sample 
TABLE I. Preparation conditions and structural parameters for the Pd particles on $\mathrm{Al}_{2} \mathrm{O}_{3} / \mathrm{NiAl}(110)$.

\begin{tabular}{lcc}
\hline \hline Deposition parameters & \\
Pd coverage $\left(\right.$ atoms $\left.\cdot \mathrm{cm}^{-2}\right)$ & $2.7 \times 10^{15}$ & \\
$\begin{array}{l}\text { Deposition temperature }(\mathrm{K}) \\
\text { Deposition rate }\left(\text { atoms } \cdot \mathrm{cm}^{-2} \cdot \mathrm{s}^{-1}\right)\end{array}$ & 300 & \\
& $9 \times 10^{12}$ & \\
Structural parameters & & $($ Refs. 22, 36) \\
Island density $\left(\mathrm{cm}^{-2}\right)$ & $1.0( \pm 0.2) \times 10^{12}$ & (Refs. 22, 36) \\
Number of Pd atoms/island & $\sim 2700$ & (Refs. 22, 36) \\
Fraction of support covered by Pd & $0.20( \pm 0.02)$ & $($ Refs. 22, 36) \\
Fraction of surface Pd atoms & $0.20( \pm 0.03)$ & (Refs. 22, 36) \\
Average island size & $5.5 \pm 0.7 \mathrm{~nm}$ & $($ Refs. 16, 22, 24) \\
Epitaxial orientation & $(111)$ & (Refs. 22, 24) \\
Island structure & crystalline, predominantly (111) facets, & \\
& small fraction of $(100)$ facets & \\
\hline
\end{tabular}

surface. The $\mathrm{CO}$ and $\mathrm{O}_{2}$ beams, which were mainly used in the work presented here, are generated by two effusive sources based on multichannel arrays. This design allows an easy variation of the beam intensities over several orders of magnitude, without any change in the beam properties. Beam modulation is provided by a computer-controlled shutter located inside the second pumping stage of the beam sources. To avoid artifacts due to only partial overlap, the beam diameter was chosen such that it exceeds the sample surface. The mean beam intensity variation over the sample surface was determined to be $6 \%$. The average variation in the $\mathrm{CO} / \mathrm{O}_{2}$ beam intensity ratio over the sample surface was estimated to be less than $2 \%$ (from beam profile measurements). Both sources were operated at room temperature. High purity oxygen (AGA, >99.999\%) and CO (AGA, $>99.996 \%$ ) were used, the latter of which was further purified using a $l-\mathrm{N}_{2}$ cold trap;. The beam intensities and profiles were measured with a beam monitor as described elsewhere. ${ }^{39}$ In order to avoid artifacts due to an effusive gas load upon closed beam at extreme $\mathrm{CO} / \mathrm{O}_{2}$ flux ratio, the $\mathrm{CO}_{2}$ transients were recorded by opening/closing the inlet valves of the beam sources (pressure rising/dropping time, 500/ $2000 \mathrm{~ms}$ ). The transient $\mathrm{CO}_{2}$ peaks observed were in all cases significantly slower than the $\mathrm{CO}$ pressure change. At moderate flux ratio transients were recorded by modulating the beam source via the internal shutter (opening/closing time, $50 \mathrm{~ms}$ ) to verify that there was no significant influence of the modulation procedure on the transient behavior. The third source generates a beam from a supersonic expansion and has not been used in the present study.

Angular-integrated gas phase measurements were performed with a quadrupole mass spectrometer (ABB Extrel) which is not in line-of-sight of the sample. Additionally, the systems allows time- and angular-resolved measurements via a differentially pumped rotatable quadrupole mass spectrometer. The gas phase detection can be combined with timeresolved in situ FT-IR reflection absorption spectroscopy (TR-IRAS) employing a vacuum FT-IR spectrometer (Bruker IFS 66 v). For the time resolved spectra with a temporal resolution of $1 \mathrm{~s}$ several transients were accumulated to improve the signal to noise ratio. For this purpose the beam shutter was synchronized with the recording of the IR spectra. Additionally, a MIR polarizer was used to select only the $p$-component of the IR light and thus further improve the $\mathrm{S} / \mathrm{N}$ ration. For a detailed description of the experimental details we again refer to the literature. ${ }^{39}$ All spectra were recorded at a spectral resolution of $8 \mathrm{~cm}^{-1}$. The total acquisition time for the in situ IR spectra was typically 50 s/spectrum and for the TR-IR spectra $5 \mathrm{~s} /$ spectrum.

Briefly, the sample was prepared by sputtering and annealing of a $\mathrm{NiAl}(110)$ single crystal, followed by an oxidation and annealing procedure, the details of which are given elsewhere. ${ }^{20,21}$ The cleanliness and quality of the oxide film was checked via LEED and AES. Before the actual experiment, the active metal component $(\mathrm{Pd},>99.9 \%)$ was deposited under well controlled conditions by evaporation from a rod (1 mm diam) using a commercial evaporator (Focus, EFM 3) based on electron bombardment. During deposition, the crystal was biased with a retarding voltage in order to prevent ions from being accelerated towards the sample (point defect creation). The evaporator flux was calibrated by a quartz microbalance prior to use. Details concerning typical deposition rates and conditions are given in Table I. After preparation the $\mathrm{Pd}$ particles were stabilized by oxygen and $\mathrm{CO}$ exposure as discussed previously. ${ }^{36}$

\section{RESULTS AND DISCUSSION}

\section{A. Characterization of the structural and adsorption properties of the supported Pd model catalyst}

The growth and structure of Pd deposits as well as other metals on $\mathrm{Al}_{2} \mathrm{O}_{3} / \mathrm{NiAl}(110)$ has previously been studied over a wide range of conditions and the results have been extensively reviewed, recently. ${ }^{16,17,22-24}$ In this work, we will focus on one particular set of preparation conditions (substrate temperature, $300 \mathrm{~K} ; \quad \mathrm{Pd}$ coverage, 2.7 $\times 10^{15}$ atoms $\mathrm{cm}^{-2}$ ), for which detailed information on both the particle size and density and on the particle structure is available. In the following, we will briefly review the main features of this system. In Figs. 2(a) and 2(b) STM images (CCT, Constant Current Topography, from Ref. 36) are shown. The Pd particles form three-dimensional islands; their density typically amounts to $1 \times 10^{12}$ islands $\mathrm{cm}^{-2}$. From this number it can be estimated that the average $\mathrm{Pd}$ particle will contain about 2700 atoms, corresponding to an average particle size of $5.5 \pm 0.7 \mathrm{~nm}$. Please note that in the 

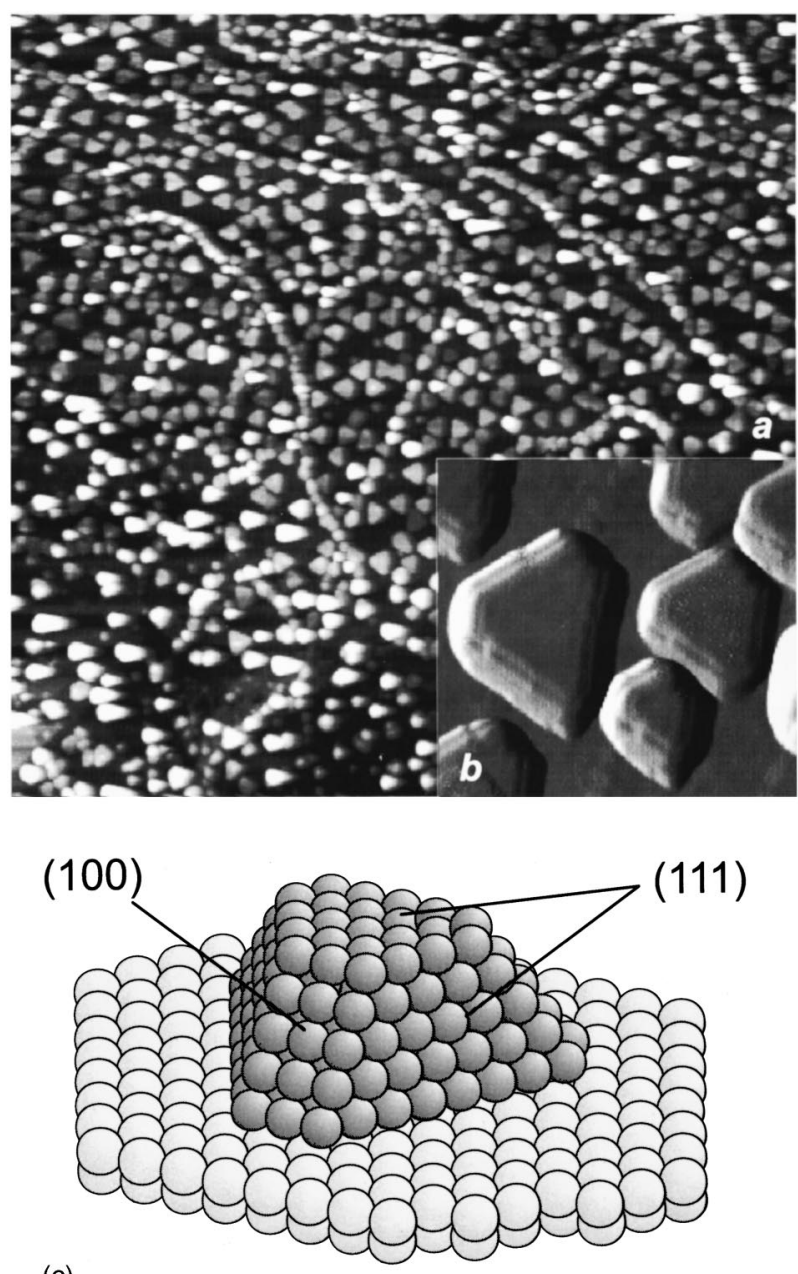

(c)

FIG. 2. (a) STM image (CCT, Constant Current Topography, $3000 \AA$ $\times 3000 \AA$ ) of the $\mathrm{Pd}$ particles grown at $300 \mathrm{~K}$ on $\mathrm{Al}_{2} \mathrm{O}_{3} / \mathrm{NiAl}(110)$, from Ref. 36; (b) differentiated close-up STM image of the Pd particles (CCT, Constant Current Topography, $3000 \AA \times 3000 \AA$ ), from Ref. 36; (c) schematic representation of a supported Pd particle.

STM image the islands appear larger than the above value due to an instrumental convolution with the tip shape. As a consequence of preferential nucleation the island appear not to be completely homogeneously distributed over the support but will decorate oxide point and line defects (e.g., domain boundaries, see Ref. 21). In the close-up shown in Fig. 2(b), it becomes evident that most of the Pd particles exhibit the well-defined morphology of a nanocrystallite. As indicated in the schematical representation [Fig. 2(c)], the particles grow in (111)-orientation, preferentially exposing (111)facets and only a small fraction of (100)-facets. The regular structure of the Pd crystallites has been demonstrated in a recent STM study showing atomic resolution both on the top and side facets of the particles. ${ }^{24}$ This and other structural information, which will be used in the following discussion, is summarized in Table I.

Before the kinetic experiments the particles were stabilized by extended oxygen exposure (typically $\sim 100 \mathrm{~L}, 1 \mathrm{~L}$ $=1 \times 10^{-6}$ Torr $\mathrm{s}$ ), followed by several $\mathrm{CO}$ oxidation cycles of the type shown in this work. This stabilization procedure has been shown to be necessary to obtain a stable oxidation kinetics. ${ }^{36}$ As observed by STM,$^{36}$ neither the particle density nor the particle shape are significantly affected by the procedure. The chemical processes related to the stabilization procedure will be discussed elsewhere. ${ }^{40}$

Two types of experiments were performed to ensure that the model surface principally resembles the behavior of a typical Pd surface: (1) We have probed the CO adsorption/ desorption kinetics employing modulated molecular beam techniques. In a temperature region from 430 to $530 \mathrm{~K}$, we have determined an activation energy for desorption of 136 $\pm 9 \mathrm{~kJ} \mathrm{~mol}^{-1}$ and a pre-exponential factor of $10^{14.9 \pm 0.9} \mathrm{~s}^{-1}$ from the temperature dependence of the $\mathrm{CO}$ residence time in the low CO coverage region. Details of the experiment will be given elsewhere. ${ }^{41}$ This value is in excellent agreement with experiments on a $\mathrm{Pd}(111)$ single crystal [desorption energy, $134 \pm 8 \mathrm{~kJ} \mathrm{~mol}^{-1}$, pre-exponential factor, $10^{14.4 \pm 0.8} \mathrm{~s}^{-1}$ (Ref. 30)]. (2) The activation barrier for the Langmuir-Hinshelwood reaction step has been determined in a series of beam experiments at high oxygen (and $\mathrm{CO}$ ) coverages. ${ }^{36}$ The apparent activation barriers of 62 $\pm 8 \mathrm{~kJ} \mathrm{~mol}^{-1}$ (and $59 \pm 8 \mathrm{~kJ} \mathrm{~mol}^{-1}$ ) are as well in good agreement with $\operatorname{Pd}(111)$ single crystal data $\left[59 \pm 8 \mathrm{~kJ} \mathrm{~mol}^{-1}\right.$ (Ref. 29)] under similar conditions. Thus we conclude that the general adsorption and reaction behavior of the supported model catalysts under consideration appears rather similar to that of a $\operatorname{Pd}(111)$ single crystal surface In the following sections we will investigate the steady state and in particular the transient $\mathrm{CO}_{2}$ production in more detail. Thus we will attempt to elucidate, whether the reaction behavior of the system may still differ from the single crystal and how these differences might be addressed experimentally.

\section{B. General types of transient behavior}

Before we come to a systematic discussion of the transient and steady-state behavior of the $\mathrm{CO}$ oxidation, we will give a short description on how most of the experiments in this study were performed and how the different types of transients can be qualitatively understood.

The general types of $\mathrm{CO}_{2}$ transients are shown in Fig. 3. The corresponding experiments were performed in the following manner: After preparation and stabilization of the model system, the surface is continuously exposed to an $\mathrm{O}_{2}$ beam with a beam flux $F_{\mathrm{O}_{2}}$, generated by one of the effusive beam sources (see Fig. 1). The integral $\mathrm{CO}_{2}$ production rate is recorded simultaneously. At a time $t_{\mathrm{CO} \text {,on }}$ (see Fig. 3) a CO beam with a beam flux $F_{\mathrm{CO}}$, generated by the second effusive source (see Fig. 1), is switched on. As flux parameters we define (1) $x_{\mathrm{CO}}$, the $\mathrm{CO}$ fraction with respect to the total flux, as

$$
x_{\mathrm{CO}}=\frac{F_{\mathrm{CO}}}{F_{\mathrm{CO}}+F_{\mathrm{O}_{2}}}
$$

and (2) $p_{\text {total }}$, the total effective pressure of $\mathrm{CO}$ and $\mathrm{O}_{2}$ at the sample position,

$$
p_{\text {total }}=p_{\mathrm{CO}}+p_{\mathrm{O}_{2}} \quad \text { with } \quad p_{i}=F_{i}\left(2 \pi m_{i} k T\right)^{0.5},
$$




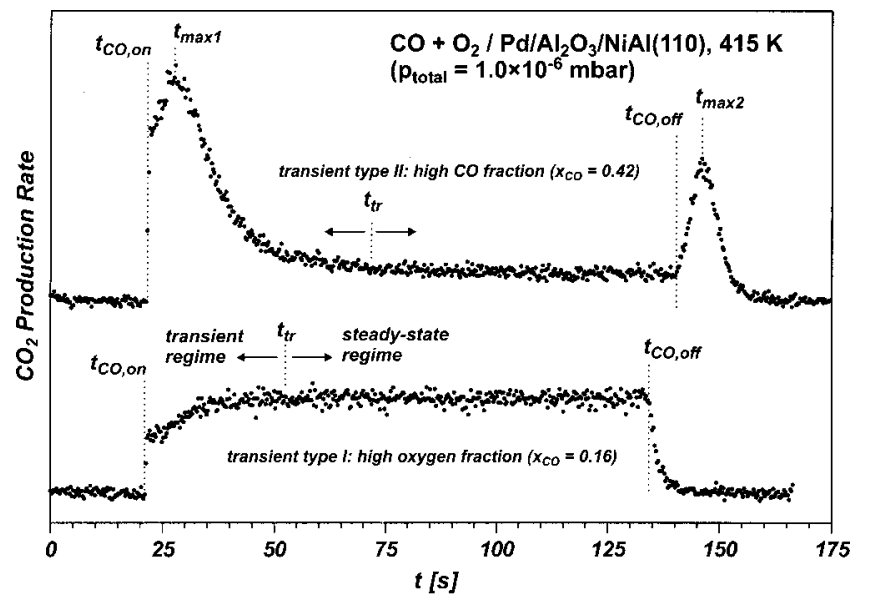

FIG. 3. Transient behavior of the $\mathrm{CO}_{2}$ production rate (continuous $\mathrm{O}_{2}$ beam and a modulated $\mathrm{CO}$ beam) under $\mathrm{CO}$-rich conditions (upper trace, transient type II) and $\mathrm{O}_{2}$-rich conditions (lower trace, transient type $\left.\mathrm{I}\right)\left(T_{\text {Sample }}\right.$ $=415 \mathrm{~K}, p_{\text {total }}=1.0 \times 10^{-6} \mathrm{mbar}$ ).

where $F_{i}$ is the partial flux of component $i$ at the sample position, $m_{i}$ represents its molecular mass, and $T_{i}$ is the temperature describing the velocity distribution (please note that $T_{i}=300 \mathrm{~K}$ as there is no cooling of any degree of freedom in the effusive sources). Typically, in a series of experiments, the CO flux fraction was varied, whereas the other parameters such as the total effective pressure, the sample temperature etc. were kept constant.

In general two different types or transients can be observed as a function of the $\mathrm{CO}$ flux fraction, which, in the following, we will denote as type 1 and type 2 (see Fig. 3), respectively. The initial transient behavior has recently been discussed by Piccolo et al. ${ }^{42,43}$

Type 1: If the experiment is performed at low $\mathrm{CO}$ and high $\mathrm{O}_{2}$ flux, a simple type of transient behavior is observed as displayed in the lower trace in Fig. $3\left(x_{\mathrm{CO}}=0.16\right)$. We start from a situation, in which the system has reached its oxygen saturation coverage under the given flux and temperature conditions. Upon switching on the $\mathrm{CO}$ beam $\left(t_{\mathrm{CO} \text {,on }}\right)$, we find an instantaneous increase (on the time scale of the experiment) in the $\mathrm{CO}_{2}$ production. As pointed out by Piccolo et al. $^{43}$ this is due to the rapid formation of a steadystate precursor coverage. From this precursor, the $\mathrm{CO}$ molecule may either desorb or chemisorb and subsequently react to $\mathrm{CO}_{2}$. In the course of the reaction oxygen vacancies are generated, which lead to an increased adsorption probability for the $\mathrm{CO}$ precursor and thus an increase in the reaction rate. After this transient period $\left(t_{\mathrm{tr}}\right)$, the system finally reaches the steady-state reaction conditions. Please note that the steadystate is characterized by a high oxygen coverage and low $\mathrm{CO}$ coverage. After switching off the $\mathrm{CO}$ beam $\left(t_{\mathrm{CO} \text {,off }}\right)$, the adsorbed $\mathrm{CO}$ is consumed and the $\mathrm{CO}_{2}$ production rate decreases continuously.

Type 2: If an equivalent experiment is performed at sufficiently high $\mathrm{CO}$ fraction (Fig. 3, upper trace, $x_{\mathrm{CO}}=0.42$ ), a different behavior is found. Again, starting from an oxygen saturated surface, we observe an instantaneous increase in the $\mathrm{CO}_{2}$ production rate upon switching on the $\mathrm{CO}$ beam. Subsequently, the reaction rate increases slowly until it reaches a first maximum (Fig. $3, t_{\max 1}$ ). As for transient type 1 , the increasing reaction rate can be explained by an increasing chemisorption probability of the $\mathrm{CO}$ precursor, due to the decreasing oxygen coverage. ${ }^{43}$ Once a certain $\mathrm{CO}$ coverage is reached, however, the $\mathrm{CO}$ oxidation rate decreases again. This is a consequence of the strongly inhibiting effect of $\mathrm{CO}$ on the $\mathrm{O}_{2}$ adsorption (for a general discussion see, e.g., Ref. 44, and references therein). Finally, a steady-state is reached, which is characterized by a high $\mathrm{CO}$ coverage and a low reaction rate (due to the inhibiting effect of $\mathrm{CO}$ ). Once the $\mathrm{CO}$ beam is terminated $\left(t_{\mathrm{CO} \text {,off }}\right)$, the process is reversed: the adsorbed $\mathrm{CO}$ is consumed in the course of the reaction, leaving free adsorption sites for $\mathrm{O}_{2}$ adsorption. Thus the $\mathrm{O}_{2}$ adsorption is accelerated and so is the reaction rate, which reaches a maximum $\left(t_{\max 2}\right)$, before it finally decreases due to depletion of the $\mathrm{CO}$ reservoir.

\section{Catalyst stability under reaction conditions}

In a second step, we will briefly consider the catalyst stability under the reaction conditions applied in this study. There are two main processes which may have an influence on the catalytic activity: (1) Prolonged exposure to the reactant gases in combination with elevated reaction temperatures may lead to structural rearrangements or changes in the particle dispersion. For example, in a recent study it has been shown that Pd particles may undergo drastic shape variations under the influence of oxygen. ${ }^{45}$ (2) $\mathrm{CO}$ dissociation may lead to a build-up of surface carbon, which may result in a deactivation of the catalyst. The formation of surface carbon has previously been observed for the $\mathrm{CO}$ oxidation reaction on small Pd particles ${ }^{46}$ and there have been indications for carbon formation on $\mathrm{Pd}$ single crystal surfaces at higher $\mathrm{CO}$ pressure. $^{47}$

Concerning a possible restructuring of the particles we refer to a previous study focusing on the interaction of oxygen with the same Pd model catalyst and its influence on the kinetics of the $\mathrm{CO}$ oxidation. ${ }^{36}$ It was shown that under the reaction conditions applied here, neither the $\mathrm{Pd}$ particle shape nor the particle dispersion are significantly affected by the oxygen pretreatment or by subsequent oxidation cycles. With respect to the possibility of surface carbon formation, we consider the experiment displayed in Fig. 4. Four different transients at high CO flux fraction (transient type II) are shown for comparison. The transients were recorded under identical conditions directly after an initial extended oxygen exposure (oxidation cycle 1), and after 1 to 22 subsequent transient experiments (see Fig. 4). It is found that neither the steady-state $\mathrm{CO}_{2}$ production rate nor the shape or the intensity of the second $\mathrm{CO}_{2}$ peak (after termination of the $\mathrm{CO}$ beam) changes as a function of reaction time. The only observable change is related to the initial $\mathrm{CO}_{2}$ production peak, which is slightly smaller during the first oxidation cycles.

As mentioned before, in a recent work employing STM, ${ }^{36}$ we could exclude major structural rearrangements such as a spreading of the Pd under the influence of the oxygen as an origin of the increased adsorption capacity after several adsorption/reaction cycles. In the same study, however, a strongly reduced $\mathrm{CO}_{2}$ peak was found before ex- 


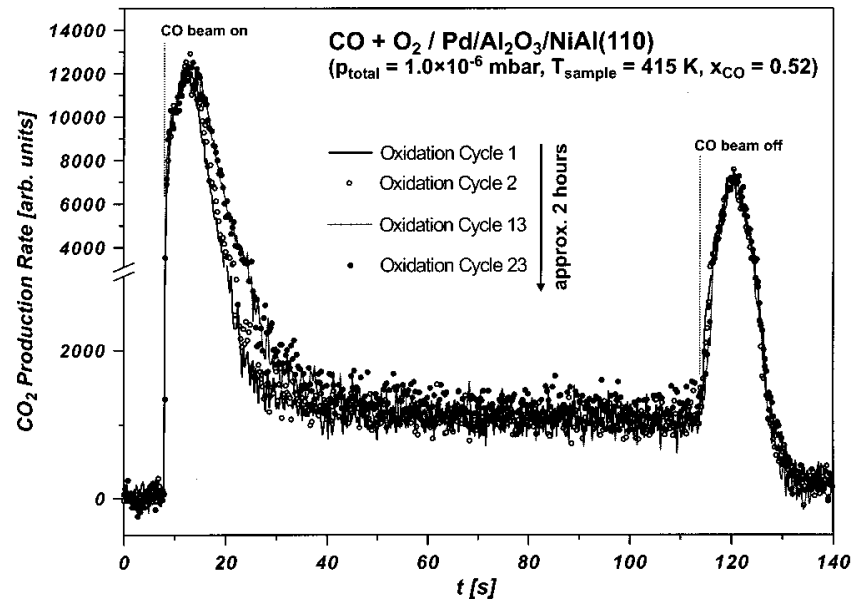

FIG. 4. Comparison of the transient behavior of the $\mathrm{CO}_{2}$ production rate under identical conditions as a function of reaction time $\left(T_{\text {Sample }}=415 \mathrm{~K}\right.$, $\left.p_{\text {total }}=1.0 \times 10^{-6} \mathrm{mbar}\right)$.

tended oxygen exposure. This observation suggests that also in the initial cycles shown in Fig. 4 the stabilization process (see Sec. III A) is not fully completed, leading to a loss of oxygen on the Pd particles during the experiment. After the initial cycles a stable oxidation kinetics evolves, showing global desorption and reaction rates consistent with previous experiments on $\mathrm{Pd}(111)$ surfaces (see Sec. III A).

Another indication that there is no significant carbon formation, is derived from the in situ IR spectra, which will be discussed in Sec. III E. For CO dissociation on $\operatorname{Pd}(111)$ Hammoudeh $^{47}$ has shown that surface carbon formation results in a strongly enhanced occupation of on-top sites. No indications for such changes have been found in the present experiments.

Thus we may conclude that under the reaction conditions and time-scales applied here, there is no substantial deactivation mechanism present, which may significantly affect the results presented in the following sections.

\section{Systematic studies of the transient behavior and steady-state $\mathrm{CO}_{2}$ production}

In order to obtain a general overview over the reaction behavior we have performed a series of transient beam experiments at different reaction temperatures. A typical series of experiments at a sample temperature of $440 \mathrm{~K}$ is displayed in Fig. 5. The sample was exposed to a continuous oxygen beam. Its intensity was chosen such that the total effective pressure after switching on the $\mathrm{CO}$ beam was $p_{\text {total }}=1.0$ $\times 10^{-6}$ mbar. The $\mathrm{CO}$ flux fraction $x_{\mathrm{CO}}$ was varied between 0.05 and 0.95 and for each $x_{\mathrm{CO}}$ a transient was recorded.

In general, we find the two types of transient behavior, discussed in Sec. III B. For $x_{\mathrm{CO}} \leqslant 0.37$ the transients are of type 1 (oxygen-rich steady state, see Fig. 3), whereas for $x_{\mathrm{CO}} \geqslant 0.47$ we find a $\mathrm{CO}$ rich steady-state, connected with the characteristic $\mathrm{CO}_{2}$ production rate maxima (transient type 2). The transition region between the two regimes will be discussed separately in Sec. III F.

We start considering some basic features of the experiment. With respect to the characteristics of the first transient $\mathrm{CO}_{2}$ peak, it is found that the time constant at which the steady-state is reached after switching on the $\mathrm{CO}$ beam diverges close to the transition region. This is easy to understand as the $\mathrm{CO}$ coverage is build up by the excess of adsorbed $\mathrm{CO}$ (not consumed during the reaction), which vanishes at the transition between the two regimes. The integral below the transient peak, however, remains nearly constant for $x_{\mathrm{CO}} \geqslant 0.52$. This is explained by the fact that the peak integral roughly corresponds to the oxygen precoverage, which is constant and will be fully consumed during the reaction. Contrary to the first transient peak, the width of the second transient peak (upon switching off the $\mathrm{CO}$ beam) increases with increasing $x_{\mathrm{CO}}$ since the $\mathrm{O}_{2}$ flux and therefore the reaction rate decreases. The integral over the second transient peak as a function of $x_{\mathrm{CO}}$ will be considered in detail in Sec. III F. It corresponds to the fraction of $\mathrm{CO}$ adsorbed in the steady-state that upon termination of the $\mathrm{CO}$ beam will not desorb but react to $\mathrm{CO}_{2}$. In general, it will show a steplike behavior similar to the first transient peak. In contrast to the adsorbed oxygen, the $\mathrm{CO}$, however, may desorb on the time-scale of the reaction at high reaction temperatures and low $\mathrm{O}_{2}$ flux, which may lead to a decreasing peak integral at high $x_{\mathrm{CO}}$.

From the transients in Fig. 5 we can derive a plot of the steady state reaction rate as a function of the $\mathrm{CO}$ flux fraction $x_{\mathrm{CO}}$ as displayed in Fig. 6. Qualitatively, it can be understood as follows: At low $x_{\mathrm{CO}}$ (on the oxygen-rich side), the $\mathrm{CO}_{2}$ production is proportional to the $\mathrm{CO}$ partial pressure. It reflects the sticking coefficient of $\mathrm{CO}$ under the particular steady-state conditions, i.e., under high oxygen and low $\mathrm{CO}$ coverage. At a certain critical $x_{\mathrm{CO}}$, the system switches from

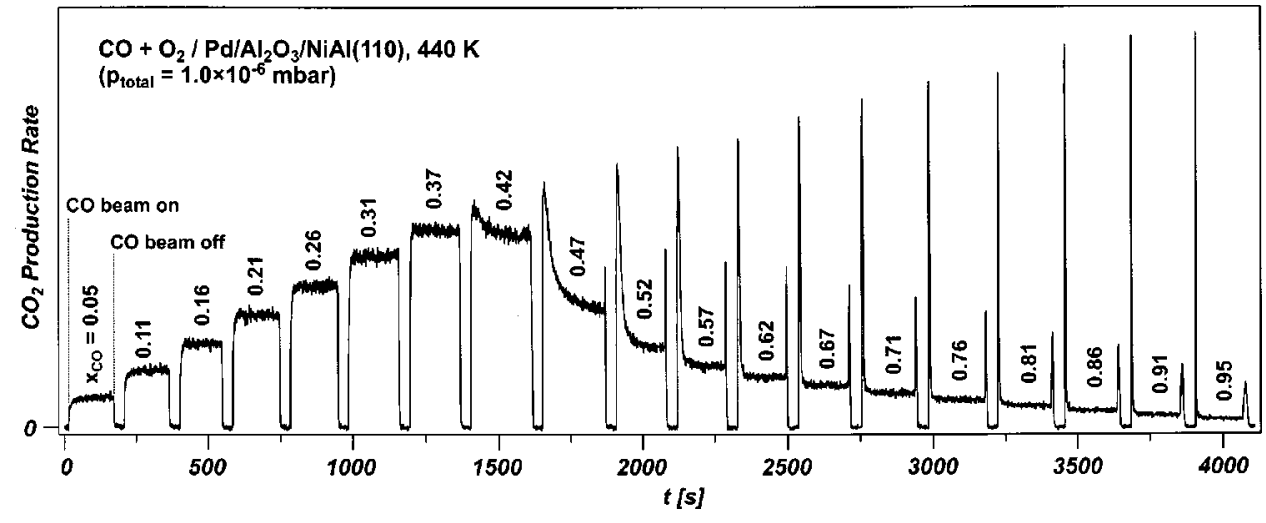

FIG. 5. Transient behavior of the $\mathrm{CO}_{2}$ production rate as a function of the $\mathrm{CO}$ fraction in the impinging gas flux $x_{\mathrm{CO}} \quad\left(T_{\text {Sample }}=440 \mathrm{~K}, \quad p_{\text {total }}=1.0\right.$ $\left.\times 10^{-6} \mathrm{mbar}\right)$ 


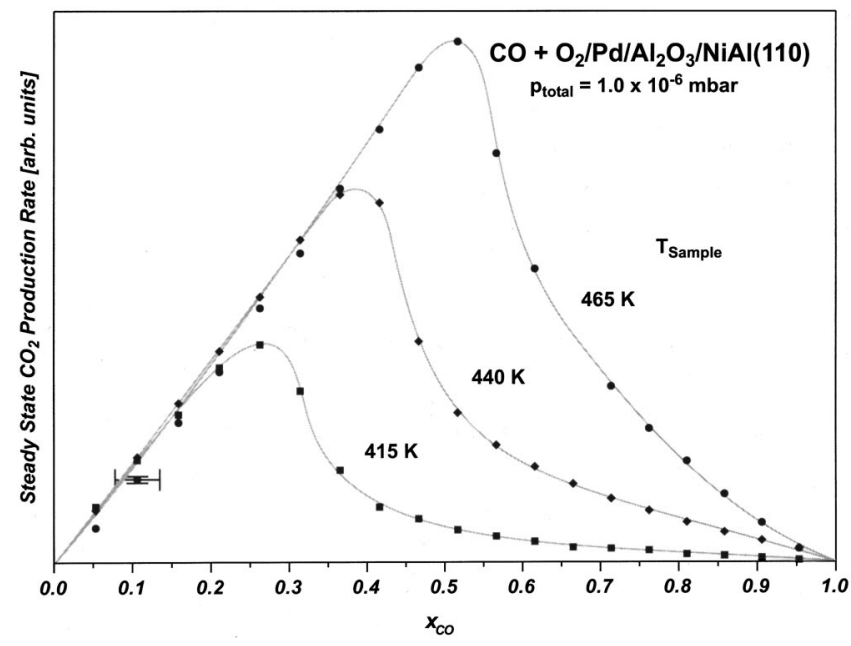

FIG. 6. Steady-state $\mathrm{CO}_{2}$ production rate as a function of the $\mathrm{CO}$ fraction in the impinging gas flux $x_{\mathrm{CO}}\left(p_{\text {total }}=1.0 \times 10^{6} \mathrm{mbar}\right)$.

an oxygen-rich to a CO-rich steady-state. This transition appears to occur continuously over a significant range of flux ratios, which will be discussed in detail in Secs. III F-III H. The transition is connected to a sudden decrease in the reaction rate as a consequence of the inhibiting effect of $\mathrm{CO}$ on the dissociative adsorption of $\mathrm{O}_{2}$ (see, e.g., Ref. 44).

Comparing the three different reaction temperatures displayed, we find a behavior which is easily explained qualitatively: In the low $\mathrm{CO}$ coverage region, the reaction rate is almost independent of reaction temperature. This indicates similar steady-states under these conditions which are close to oxygen saturation. Generally, the CO sticking coefficient, which governs the reaction rate, is expected to decrease slightly with increasing temperature due to the decreasing lifetime of the $\mathrm{CO}$ precursor state both on the alumina substrate and on the Pd particles. This effect, however, is too weak to be identified clearly from the present data. Note that although the CO steady-state coverage is small, it will depend on the reaction temperature, i.e., the steady-state $\mathrm{CO}$ coverage will increase with decreasing surface temperature. Therefore, at low temperature the transition point, at which due to inhibition of oxygen adsorption the system switches to the CO-rich state, is reached at lower $x_{\mathrm{CO}}$. In the high $\mathrm{CO}$ coverage region the rate is limited by the oxygen adsorption step. The reaction rates do not coincide due to the increased $\mathrm{CO}$ steady-state coverage at lower temperatures (slower desorption and reaction rates) which give rise to an increased inhibition of the $\mathrm{O}_{2}$ adsorption.

Similar data have been derived for the $\mathrm{CO}$ oxidation on a number of catalytically active transition metal surfaces. As the most relevant reference case we briefly consider the work of Hammoudeh, ${ }^{47}$ who has studied the $\mathrm{CO}$ and $\mathrm{O}_{2}$ adsorption and $\mathrm{CO}$ oxidation on $\mathrm{Pd}(111)$ applying in situ IR and workfunction measurements. It was shown that the reaction rate on $\operatorname{Pd}(111)$ exhibits a rather complex behavior, showing two maxima/hysteresis regions as a function of the reactant fluxes. Both strongly depend on certain internal parameters such as the pretreatment of the sample. Hammoudeh connected the first maximum to the inhibition effect explained above and tentatively assigned the second maximum to reactivity variations related to changes in the dispersion of adsorbed CO islands. In the case of small metal particles, the formation of large adsorbate islands may be prevented by the limited size of the crystallite facets. This, as a general difference between single crystal and supported particle systems, may-among other effects-give rise to a suppression of a second reactivity maximum and thus to a simpler overall behavior of the reaction system.

Moreover, it was observed in the same study ${ }^{47}$ that the kinetics is not stable under certain reaction conditions, but gradually changes during the reaction itself. This behavior was related to the slow formation of subsurface and bulk oxygen and the situation was found to be stabilized after prolonged oxygen exposure. In accordance with this interpretation, we find that the oxygen-pretreated particles used in this study, show a stable oxidation kinetics, even after repeated oxidation-reduction cycles.

In future work, the data of the type presented here, may provide a basis for more extensive microkinetic simulations of the steady state and transient reaction behavior. It has to be pointed out that such simulations-in connection with steady-state reaction rate measurements for different types of structurally well-characterized supported model catalystsmay be an excellent tool to identify kinetic effects characteristic for supported nanoparticles. ${ }^{5}$ In a recent series of papers Zhdanov and Kasemo have discussed this issue ${ }^{5-7}$ in connection with two types of effects, namely, the influence of communication between different facets on the nanocrystallites and the role of support mediated adsorption.

\section{E. In situ IR absorption spectroscopy under steady- state conditions}

In order to obtain further insight into the occupation of $\mathrm{CO}$ adsorption sites under steady-state conditions, we have acquired IR reflection absorption spectra under reaction conditions. The spectra were taken after the steady-state was reached in transient experiments of the type shown in Fig. 5. For the example displayed in Fig. 7 the surface temperature was $415 \mathrm{~K}$.

Based on a comparison with IR spectra of $\mathrm{CO}$ on different Pd single crystal surfaces, ${ }^{48-55}$ we may assign the observed features. Tüshaus, ${ }^{52}$ for example, has studied $\mathrm{CO}$ on clean and roughened $\mathrm{Pd}(111)$ surfaces. Hammoudeh ${ }^{47}$ has investigated the coadsorption of oxygen and $\mathrm{CO}$ using IR spectroscopy. The spectral features observed for $\mathrm{CO}$ adsorbed on $\mathrm{Pd}$ particles supported on $\mathrm{Al}_{2} \mathrm{O}_{3} / \mathrm{NiAl}(110)$ were previously investigated by Wolter et al. ${ }^{23}$ over a large range of surface coverages and at different sample temperatures. At room temperature (and above) three types of adsorbed $\mathrm{CO}$ can be identified. At low coverage $\mathrm{CO}$ adsorbed in hollow sites is the dominating species $\left(\sim 1830 \mathrm{~cm}^{-1}\right)$, mainly from threefold hollow sites on the (111)-facets, since there will be only a small fraction of $\mathrm{CO}$ adsorbed on the minority of (100) sites and the signal will be additionally damped due to the inclination angle with respect to the sample. With increasing coverage an increasing occupation of bridge sites $\left(\sim 1900-1950 \mathrm{~cm}^{-1}\right)$ is observed. In contrast to low sample temperatures, however, thermal line-broadening at room 


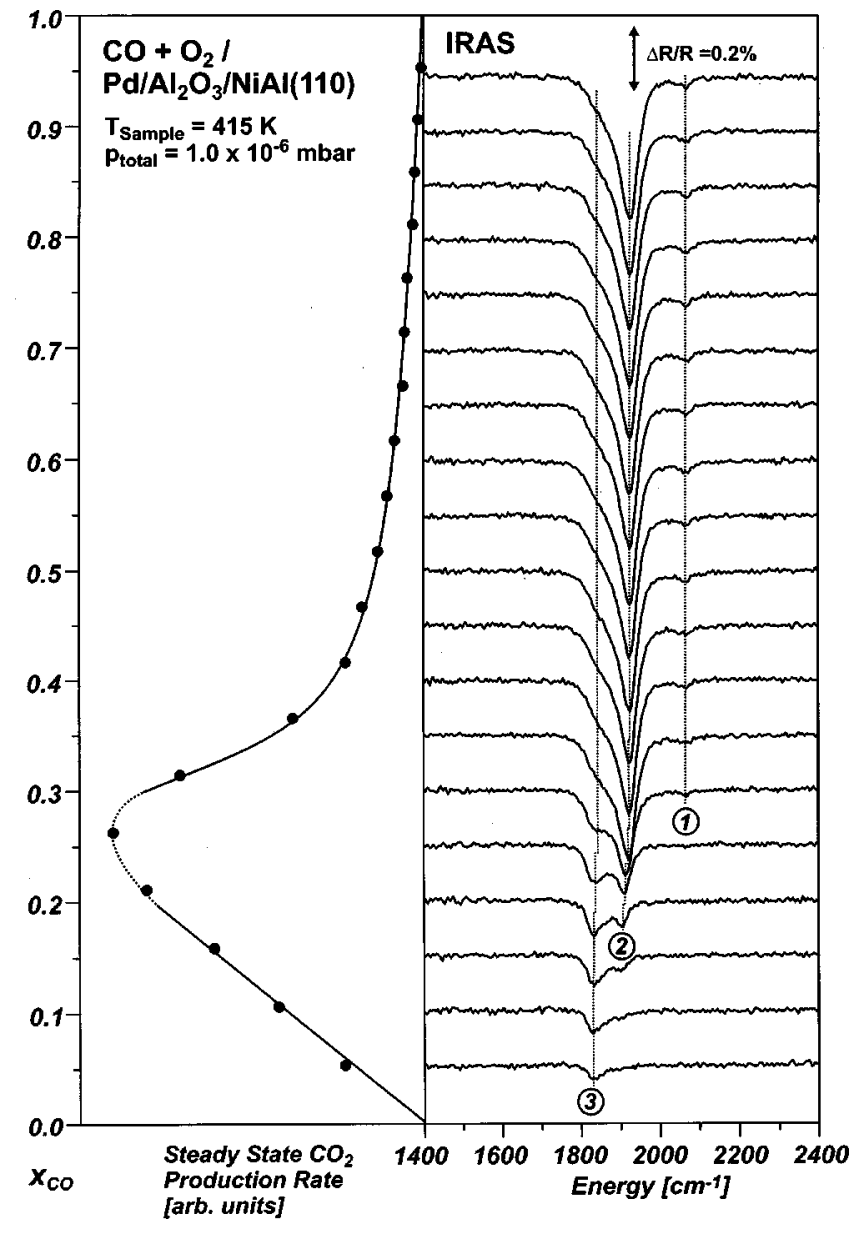

FIG. 7. In situ IR reflection absorption spectra under steady-state reaction conditions as a function of the $\mathrm{CO}$ fraction in the impinging gas flux $x_{\mathrm{CO}}$ $\left(T_{\text {Sample }}=415 \mathrm{~K}, p_{\text {total }}=1.0 \times 10^{-6} \mathrm{mbar}\right)$.

temperature and higher prevents a differentiation between $\mathrm{CO}$ bonded to regular and defect sites. ${ }^{23}$ With the surface coverage increasing further, a weak absorption signal in the energy region typical for terminally bonded $\mathrm{CO}$ appears $\left(\sim 2060 \mathrm{~cm}^{-1}\right)$.

Qualitatively, the CO spectra under steady state reaction conditions (Fig. 7) appear very similar to the observations for adsorption of pure $\mathrm{CO}$ described above. $\mathrm{CO}$ bonded in hollow sites (Fig. 7, No. 3), in bridge sites (Fig. 7, No. 2) and on-top CO (Fig. 7, No. 1) can be distinguished. The quantitative development of the IR spectra as a function of $x_{\mathrm{CO}}$ is displayed in Fig. 8. The integral $\mathrm{CO}$ absorption signal [Fig. $8(\mathrm{a})$, regime I] initially (below $x_{\mathrm{CO}}=0.2$ ) increases almost linearly with increasing $\mathrm{CO}$ flux fraction. This observation is in line with a $\mathrm{LH}$ rate constant being largely independent of CO coverage in the low CO flux limit (note that the IR absorption will be almost linear with the coverage in the low coverage limit, whereas at high coverages strong deviations may occur, see, e.g., Refs. 48, 56-58). In the transition region (Fig. 8, regime II), where the systems switches to the $\mathrm{CO}$-rich reaction regime, the $\mathrm{CO}$ absorption signal increases rapidly, indicating also a sudden increase in $\mathrm{CO}$ coverage. From this point on (Fig. 8, regime III, $x_{\mathrm{CO}}>0.4$ ), hardly any further changes can be detected in the $\mathrm{CO}$ absorption spectrum.

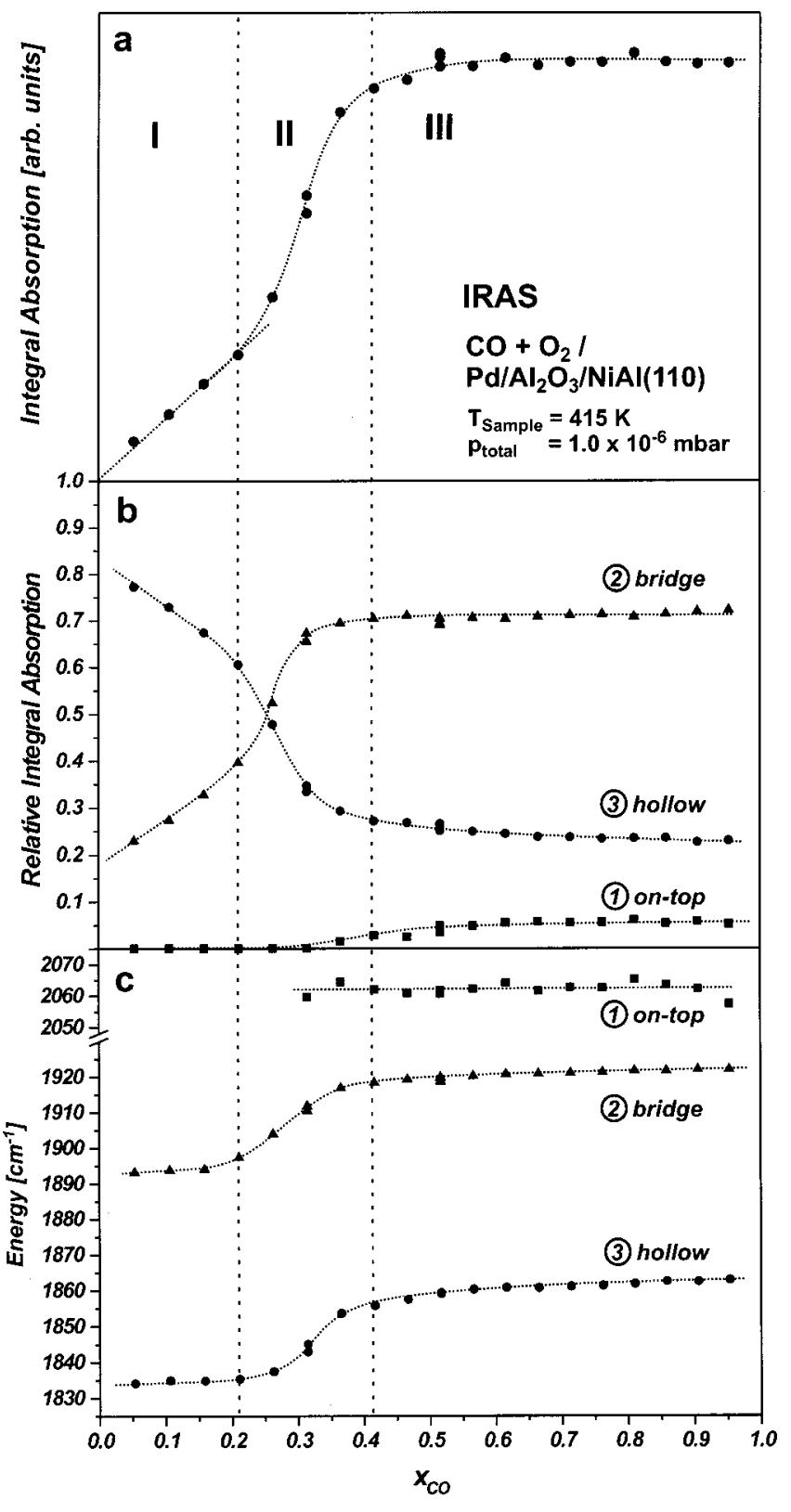

FIG. 8. (a) Integral absorption for the IRA spectra presented in Fig. 7; (b) relative absorption in the regions characteristic for $\mathrm{CO}$ adsorbed in (1) ontop, (2) bridge-bonded, and (3) hollow sites; (c) vibrational frequencies of the CO species marked in (b). Additionally, the oxygen-rich region (I), the CO-rich region (III), and transition regime (II) are indicated.

Figure 8(b) shows the relative fraction of the three principal $\mathrm{CO}$ species as derived from a fit of the spectra displayed in Fig. 7. At low $x_{\mathrm{CO}}, \mathrm{CO}$ in hollow sites represents the majority species. The fraction of bridge $\mathrm{CO}$ increases slowly with increasing $\mathrm{CO}$ fraction, before in the transition regime a sudden increase in the population of bridge sites is observed, whereas the signal from the $\mathrm{CO}$ in hollow sites remains almost constant. Simultaneously, a small fraction of CO populates on-top sites. In comparison to single crystals, this on top signal under steady-state conditions appears at lower energies $\left(2062 \mathrm{~cm}^{-1}\right)$ and is present at lower sample temperatures (Ref. 47, see also Refs. 51 and 53). This effect may be related to adsorption at typical defect sites on the supported particles such as steps or edges. 
In Fig. 8(c) we investigate the influence of the $\mathrm{CO}$ flux fraction $x_{\mathrm{CO}}$ on the $\mathrm{CO}$ stretching frequency. The data was also derived from fits of the spectra displayed in Fig. 7. As has been discussed early (see, e.g., Ref. 59, and references therein), the $\mathrm{CO}$ stretching frequency may serve as a measure of the local CO density. The shifts are mainly due to two effects, namely changes in the $\mathrm{CO}-\mathrm{Pd}$ bonding induced by neighboring $\mathrm{CO}$ molecules (chemical effects) or by coupling of the dynamic dipoles. ${ }^{59}$ Quantitatively, the contributions for $\operatorname{Pd}(111)$ have been estimated by Tüshaus. ${ }^{52}$ It has to be pointed out that a quantitative relation of the $\mathrm{CO}$ stretching frequency to the local $\mathrm{CO}$ coverage is complicated by the influence of coadsorbed oxygen, which also perturbs the electronic structure of $\mathrm{Pd}$ and thus the $\mathrm{Pd}-\mathrm{CO}$ bond. For example, Hammoudeh ${ }^{47}$ has shown that preadsorbed oxygen on $\mathrm{Pd}(111)$ may result in a shift of the $\mathrm{CO}$ singleton frequency from $1803 \mathrm{~cm}^{-1}$ to $1822 \mathrm{~cm}^{-1}$.

Although these effects preclude a straightforward quantitative analysis, we may, however, derive some indications on the $\mathrm{CO}$ distribution from the vibrational frequencies displayed in Fig. 8(c). Up to a $x_{\mathrm{CO}}$ of 0.2 , the shift in the stretching frequency of $\mathrm{CO}$ bound to hollow sites is small $\left(\sim 1 \mathrm{~cm}^{-1}\right)$, indicating that there are only minor changes in the local environment of adsorbed CO molecules. Similarly, this observation holds for $\mathrm{CO}$ bound to bridge sites up to $x_{\mathrm{CO}} \leqslant 0.2$. Thus, we may conclude that the formation of increasingly large $\mathrm{CO}$ islands under these conditions is unlikely and the $\mathrm{CO}$ can be anticipated to exist in a largely diluted form in an oxygen-rich surrounding. The local $\mathrm{CO}$ density changes suddenly and almost exclusively in the transition range between the oxygen-rich and the $\mathrm{CO}$ rich regime. This is indicated by a shift of approximately $28 \mathrm{~cm}^{-1}$ to higher frequency, both for the $\mathrm{CO}$ in bridge and hollow sites.

The transition between the two regimes, however, does not show a step-like behavior, but continuously extends over a finite range of $x_{\mathrm{CO}}$ values. This effect will be further discussed in the following sections.

\section{F. Transient CO switching-off behavior}

Among the different kinetic effects on supported catalysts, surface diffusion mediated coupling between different types of adsorption sites has recently attracted considerable attention. ${ }^{5-7}$ The presence of different types of adsorption sites in close proximity is an intrinsic property of complex catalytic systems. Such types of adsorption sites may, e.g., be different facets on nanocrystallites, step, edge or other defect sites, interface sites located at the particle boundary or adsorption sites on the support material itself. Zhdanov and Kasemo ${ }^{5}$ have extensively reviewed simulations of such coupling processes. They have shown that relatively moderate changes in the sticking coefficients or reaction/adsorption energetics may drastically change the reaction rate under certain conditions.

Still, the experimental verification of these effects is not straightforward and very few examples exist in the literature. Recently, Becker and Henry have observed a transient behavior in an experiment, similar to the transient experiments shown in this work, which was related to such an heteroge- neity effect. ${ }^{4,37,38}$ Upon switching-off the $\mathrm{CO}$ beam, they observed a sudden decrease of the $\mathrm{CO}_{2}$ production rate, followed by a smaller $\mathrm{CO}_{2}$ production peak.

Becker and Henry originally suggested an explanation, ${ }^{4,37,38}$ followed by simulations, ${ }^{60}$ which involves rapid desorption of $\mathrm{CO}$ from regular sites (resulting in the rapid decrease in $\mathrm{CO}_{2}$ production). Based on previous studies, ${ }^{3,61} \mathrm{CO}$ adsorbed at low coordinated edge sites (the proportion of which is increasing with decreasing cluster size), is assumed to be bound more strongly. Thus these sites will remain fully saturated until the $\mathrm{CO}$ reservoir on the facets is largely depleted. Only after vacancies among these defect are generated, the reaction rate increases again. This effect is assumed to result in the smaller maximum in the $\mathrm{CO}_{2}$ production rate.

Since the Pd crystallites in the present study are composed of similar facets (111) and (100), a similar effect is expected for the present model system, but with a weak second peak due to the rather large particle size. Therefore, we have investigated the transient behavior under a variety of flux and temperature conditions (Fig. 9). Indeed, we find that under certain flux conditions we observe a transient $\mathrm{CO}_{2}$ peak, which appears very similar to the effect originally reported by Becker and Henry. After an initial sudden decrease in the reaction rate, the $\mathrm{CO}_{2}$ production shows a peak, which strongly depends on the experimental conditions. The effect only starts to appear close to the transition between the oxygen-rich and the $\mathrm{CO}$-rich reaction regime.

To further investigate the origin of the peak, we have systematically varied the $\mathrm{CO}$ flux fraction $x_{\mathrm{CO}}$ between both reaction regimes. The result for two reaction temperatures is displayed in Fig. 9. The inset shows the integral $\mathrm{CO}_{2}$ production in the switching-off peak. As a function of $x_{\mathrm{CO}}$ the intensity varies continuously. At high CO ratio it develops into the typical transient peak observed at high $\mathrm{CO}$ coverage, which is a simple consequence of the inhibiting effect of $\mathrm{CO}$ on the $\mathrm{O}_{2}$ adsorption. At low $\mathrm{CO}$ fraction it first decreases and finally vanishes completely.

In contrast to the previously suggested explanation, this continuous intensity variation indicates that the effect, at least for the present supported model catalyst is not related to a characteristic type of defect sites connected to the Pd particle size. Instead, the effect appears to involve all $\mathrm{CO}$ adsorption sites available on the particle.

The crucial point with respect to the previous explanation is related to the assumption that the sudden decrease in the reaction rate is related to the spontaneous desorption of $\mathrm{CO}$ upon termination of the $\mathrm{CO}$ beam. To verify, whether such an effect exists, we have performed a time-resolved in situ IRAS experiment [see Fig. 10(b)] simultaneously with the reactivity measurements [Fig. 10(a)]. Under conditions, where the sudden decrease and transient peak are observed we have recorded IR absorption spectra with a temporal resolution of $1 \mathrm{~s}$. In order to improve the signal/noise ratio the full reaction sequence was automatically repeated. In Fig. 10 , spectra which were obtained by accumulation of 5 transients are displayed. The IRA spectra (bridge and hollow absorption peaks) were integrated and the results are shown in the inset [Fig. 10(c)]. No indication for a sudden decrease 


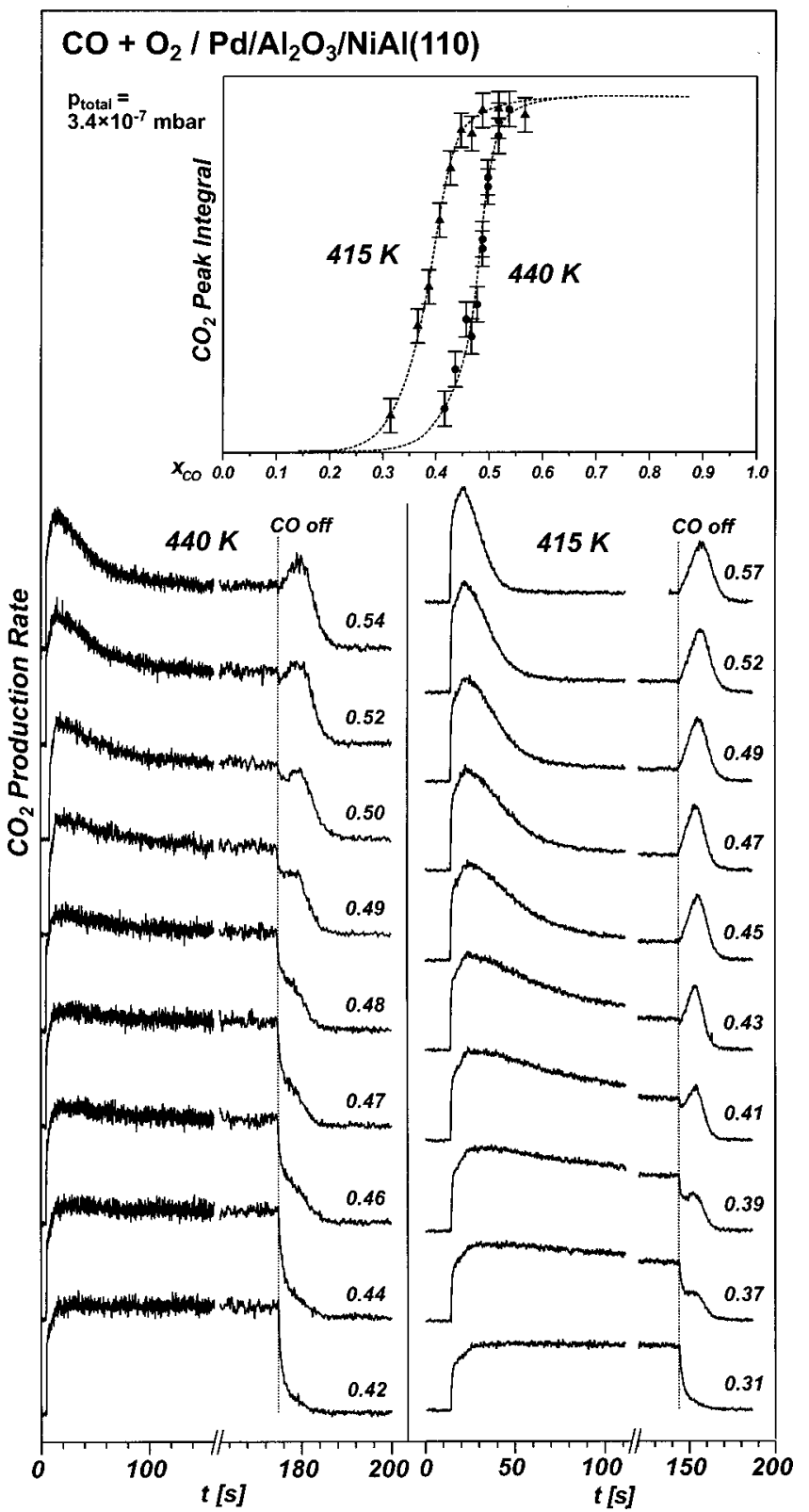

FIG. 9. Transient behavior of the $\mathrm{CO}_{2}$ production rate as a function of the $\mathrm{CO}$ fraction in the impinging gas flux $x_{\mathrm{CO}}$ close to the transition between the two reaction regimes ( $p_{\text {total }}=3.4 \times 10^{-7}$ mbar). The inset shows the integral over the peak which appears upon termination of the $\mathrm{CO}$ beam.

in the $\mathrm{CO}$ absorption signal is found. Instead the absorption peaks decreases continuously with a slope roughly resembling the reaction rate (note that due to the nonlinear coverage-absorption dependency there is no simple correspondence between the two quantities, see Sec. IIIE)

This result, in line with the previous intensity argument (Fig. 9), clearly demonstrates that the observed behavior cannot be a result of spontaneous $\mathrm{CO}$ desorption from regular sites and strong binding to defect sites. Instead, the effect appears to be related to the simple $\mathrm{CO}_{2}$ production peak under conditions of high $\mathrm{CO}$ flux. This suggestion is consistent with an estimate of the $\mathrm{CO}$ surface residence times based on the desorption data given in Sec. III A $\left(E_{a \text {,des }}=136\right.$ $\left.\pm 9 \mathrm{~kJ} \mathrm{~mol}^{-1}, A_{\mathrm{des}}=10^{14.9 \pm 0.9} \mathrm{~s}^{-1}\right)$. Using these values, we calculate a residence times of $200 \mathrm{~s}(20 \mathrm{~s})$ for a surface temperature of $415 \mathrm{~K}(440 \mathrm{~K})$ at low CO coverage. Indeed, this estimate indicates that no sudden desorption is expected on the time scale under discussion. In the following we will discuss, which alternative effects may have to be taken into consideration in order to account for the observed transient behavior.

The experiments discussed before, have shown that the $\mathrm{CO}_{2}$ peak (1) starts to appear only in the transition between the two reaction regimes and (2) is not related to specific defect sites (at least for the model system studied here). Taking this into account we may consider the following alternative explanations, which may give rise or additionally contribute to the observed effect:

(1) Local beam intensity variations: Due to beam intensity variations in the $\mathrm{CO}$ and $\mathrm{O}_{2}$ beam, the sample surface will locally be exposed to different effective pressures and flux ratios. From beam profile measurements, a standard deviation of the local pressure $p_{\text {eff }}$ of typically $\pm 6 \%$ can be estimated. The standard deviation of the flux ratio $x_{\mathrm{CO}}$ is typically $\pm 2 \%$. The width of the transition region (see Fig. 9), however, is significantly broader (typically in the order of $\pm 10 \%$ of the $x_{\mathrm{CO}}$ value at which the transition occurs). Thus, in a first approximation this contribution may be neglected.

(2) CO poisoning induced peaks: As discussed in Sec. III G, the transient behavior can be semiquantitatively simulated using a simple homogeneous "mean-field" model based on kinetic parameters from separate adsorption and reactivity studies on $\mathrm{Pd}(111)$ and the supported $\mathrm{Pd}$ particles. It is shown that the transient $\mathrm{CO}_{2}$ production rate in the transition region may show a behavior similar to the one observed experimentally, as a consequence of the competition between the decreasing $\mathrm{CO}$ coverage and increasing $\mathrm{O}_{2}$ sticking probability.

(3) Effects induced by the heterogeneity of the system: The effect, described in (2) may be additionally enhanced by the inherent heterogeneity of the supported model catalyst. On the model surface, every Pd particle represents a largely isolated reaction system. Yet, the individual adsorption and reaction rates may differ considerably. Thus, different steady states may coexist under given conditions, with the total reaction rate being a superposition of the individual states. The influence of this effect on the transients will be discussed in Sec. III H.

\section{G. Simulations}

It has been shown in the previous section that the peculiar transient behavior of the reaction rate was not related to the presence of specific highly-binding sites on the clusters. At this point it is tempting to simulate the steady state and transient experiments on the basis of a "mean-field" kinetic model of a homogeneous surface. Such modeling may provide some indications, which features may at least qualitatively be described by the simple kinetic model and where the complexity of the system will have to be explicitly considered in the model.

Let us consider a $\operatorname{Pd}(111)$ single-crystal surface. Adsorbates are supposed to be randomly distributed on this sur- 


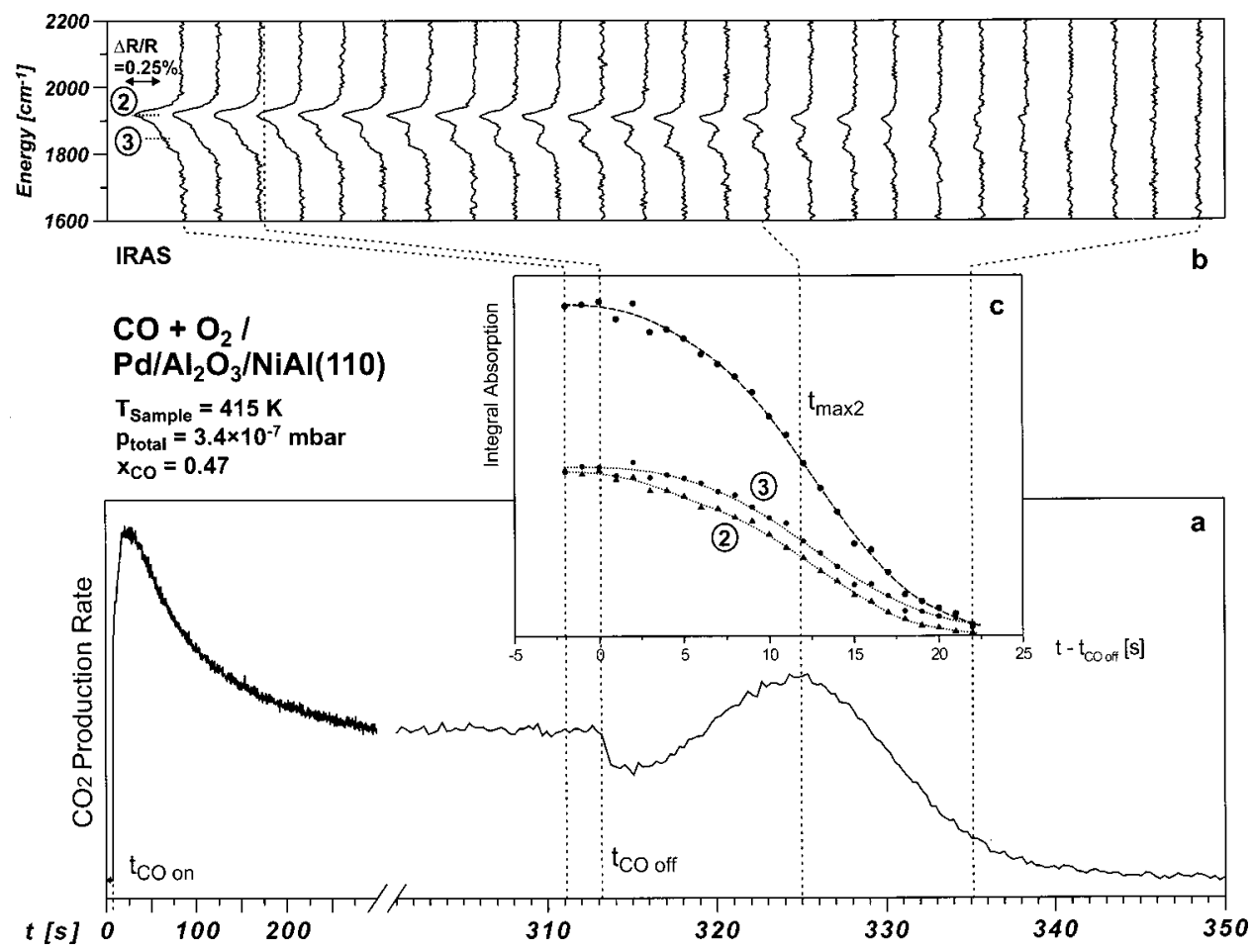

FIG. 10. Combined reactivity (a) and time-resolved IR reflection absorption experiment (b) during the transient region upon termination of the $\mathrm{CO}$ beam $\quad\left(T_{\text {Sample }}=415 \mathrm{~K}, \quad p_{\text {total }}=3.4\right.$ $\times 10^{-7}$ mbar). (c) Integral absorption for the IRA spectra presented in (b) and partial absorption in the bridge (2) and hollow (3) regions.

face. The overall $\mathrm{CO}$ oxidation reaction can be expanded in its elementary steps:

$$
\begin{aligned}
& \mathrm{CO}+s_{\mathrm{ad}}-k_{1} \rightarrow \mathrm{CO}_{\mathrm{ad}}, \\
& \mathrm{CO}_{\mathrm{ad}}-k_{2} \rightarrow \mathrm{CO}+s_{\mathrm{ad}}, \\
& \mathrm{O}_{2}+2 s_{\mathrm{ad}}-k_{3} \rightarrow 2 \mathrm{O}_{\mathrm{ad}}, \\
& \mathrm{CO}_{\mathrm{ad}}+\mathrm{O}_{\mathrm{ad}}-k_{4} \rightarrow \mathrm{CO}_{2}+2 s_{\mathrm{ad}} .
\end{aligned}
$$

$s_{\text {ad }}$ refers to a free adsorption site. $k_{i}$ is the rate constant of step $i$.

The $\mathrm{CO}_{2}$ desorption step $\left(\mathrm{CO}_{2 \mathrm{ad}} \rightarrow \mathrm{CO}_{2}\right)$ being much faster than the other steps, ${ }^{29}$ it is not necessary to expand step (4). Equations (3)-(6) can be converted to the following system of coupled differential equations, which describes the time evolution of the CO coverage $\theta_{\mathrm{CO}}$ and of the oxygen coverage $\theta_{\mathrm{O}}$ (see, e.g., Ref. 42),

$$
\frac{d \theta_{\mathrm{CO}}}{d t}=k_{1} S_{\mathrm{CO}}-k_{2} \theta_{\mathrm{CO}}-k_{4} \theta_{\mathrm{CO}} \theta_{\mathrm{O}}
$$

with

$$
\begin{aligned}
& S_{\mathrm{CO}}=S_{\mathrm{CO}}^{0}\left(1-\frac{\theta_{\mathrm{CO}}}{\theta_{\mathrm{CO}}^{\max }}-C_{T_{s}} \frac{\theta_{\mathrm{O}}}{\theta_{\mathrm{O}}^{\max }}\right), \\
& \frac{d \theta_{\mathrm{O}}}{d t}=2 k_{3} S_{\mathrm{O}_{2}}-k_{4} \theta_{\mathrm{CO}} \theta_{\mathrm{O}}
\end{aligned}
$$

with

$$
S_{\mathrm{O}_{2}}=\left\{\begin{array}{l}
S_{\mathrm{O}_{2}}^{0}\left(1-\frac{\theta_{\mathrm{CO}}}{\theta_{\mathrm{CO}}^{\max }}-\frac{\theta_{\mathrm{O}}}{\theta_{\mathrm{O}}^{\max }}\right)^{2} ; \quad 1-\frac{\theta_{\mathrm{CO}}}{\theta_{\mathrm{CO}}^{\max }}-\frac{\theta_{\mathrm{O}}}{\theta_{\mathrm{O}}^{\max } \geqslant 0} \\
0 ; \quad 1-\frac{\theta_{\mathrm{CO}}}{\theta_{\mathrm{CO}}^{\max }}-\frac{\theta_{\mathrm{O}}}{\theta_{\mathrm{O}}^{\max }}<0
\end{array} .\right.
$$

$S_{\mathrm{CO}}^{0}$ and $S_{\mathrm{O}_{2}}^{0}$ are the initial (i.e., at zero coverage) sticking coefficients of $\mathrm{CO}$ and $\mathrm{O}_{2}$, respectively. We will use $S_{\mathrm{CO}}^{0}$ $=0.96\left(\forall T_{s}\right)$ and $S_{\mathrm{O}_{2}}^{0}=0.78-7.4 \times 10^{-4} T_{s}$, where $T_{s}$ is the sample temperature. ${ }^{30}$ For the maximum coverages, we assume $\theta_{\mathrm{CO}}^{\max }=0.5$ and $\theta_{\mathrm{O}}^{\max }=0.25$. Those values correspond to the saturation coverages on $\operatorname{Pd}(111)$ at $T_{s} \geqslant 300 \mathrm{~K} .{ }^{62}$

It should be noted that we have chosen simple (not always realistic) Langmuir's Laws for the sticking coefficients. The only correction concerns the influence of preadsorbed oxygen on sticking of $\mathrm{CO}\left[C_{T_{s}}\left(\theta_{\mathrm{O}} / \theta_{\mathrm{O}}^{\max }\right)\right.$, Eq. (7)]. It has early been recognized that there is no strong inhibiting effect of preadsorbed oxygen on the sticking coefficient of $\mathrm{CO}$ on $\operatorname{Pd}(111) .{ }^{29}$ However, to account for the reaction rate at high oxygen coverage and, therefore, to produce a qualitatively correct transient behavior upon impingement of the $\mathrm{CO}$ beam on the oxygen saturated sample, this minor effect has to be taken into account. Erikson and Ekedahl ${ }^{63}$ and Piccolo et al. ${ }^{43}$ have described the inhibiting effect of oxygen introducing a temperature dependent coefficient $C_{T_{s}}$ [see Eq. (7)], which is physically related to the presence of a precursor to $\mathrm{CO}$ chemisorption. Over the limited temperature range in this study, we have neglected its moderate temperature dependence and have chosen $C_{T_{s}}=0.3$ to fit the experimental transient behavior in Fig. 5. Note that the exact choice of this parameter is not of relevance with respect to the following semiquantitative discussion.

In the case of the present experiments, the initial conditions (i.e., just before switching on the $\mathrm{CO}$ beam) are $\theta_{\mathrm{CO}}\left(t=t_{\mathrm{CO}, \text { on }}\right)=0$ and $\theta_{\mathrm{O}}\left(t=t_{\mathrm{CO}, \text { on }}\right)=\theta_{\mathrm{O}}^{\max }=0.25$. Besides, step 1 [Eq. (3)] no longer exists at $t>t_{\mathrm{CO} \text {,off }}$. Thus, the adsorption term in Eq. (7) disappears during this period. The rate constants of the four steps are 


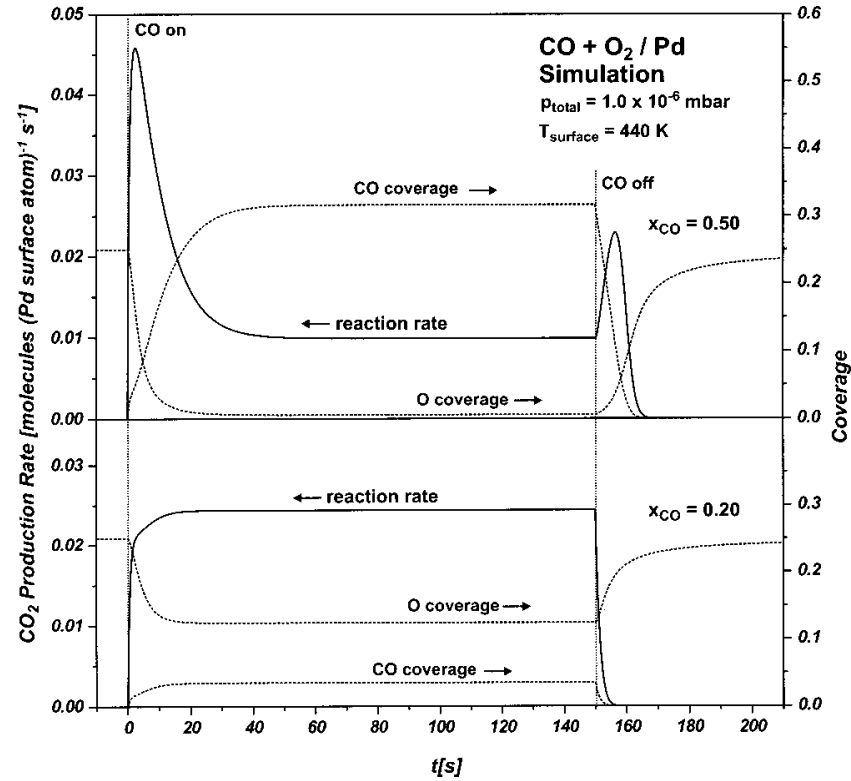

FIG. 11. Simulated transient behavior of the $\mathrm{CO}_{2}$ production rate, the $\mathrm{CO}$ coverage and the oxygen coverage for oxygen rich (bottom trace $x_{\mathrm{CO}}=0.2$ ) and $\mathrm{CO}$ rich (top trace, $\left.x_{\mathrm{CO}}=0.5\right)$ reaction conditions $\left(T_{\text {Sample }}=440 \mathrm{~K}\right.$, $\left.p_{\text {total }}=1.0 \times 10^{-6} \mathrm{mbar}\right)$.

$$
\begin{aligned}
& k_{1}=\frac{F_{\mathrm{CO}}}{n_{\mathrm{Pd}}}, \\
& k_{2}=v_{2} \exp \left(\frac{-E_{2}}{k_{B} T_{s}}\right), \\
& k_{3}=\frac{F_{\mathrm{O}_{2}}}{n_{\mathrm{Pd}}}, \\
& k_{4}=v_{4} \exp \left(\frac{-E_{4}}{k_{B} T_{s}}\right) .
\end{aligned}
$$

$n_{\mathrm{Pd}}$ is the surface density of Pd atoms on a (111) face: $n_{\mathrm{Pd}}$ $=1.53 \times 10^{15} \mathrm{~cm}^{-2} \mathrm{~s}^{-1} \cdot v_{i}$ and $E_{i}$ are the frequency factor and the activation energy related to step $i$, respectively. On the basis of the available literature, these values have been chosen as $v_{2}=10^{15.0} \mathrm{~s}^{-1}, E_{2}=136 \mathrm{~kJ} / \mathrm{mol}, v_{4}=10^{7.9} \mathrm{~s}^{-1}$, and $E_{4}=60 \mathrm{~kJ} / \mathrm{mol}$. Engel and Ertl have determined $E_{4}$ $=59 \mathrm{~kJ} / \mathrm{mol}$ (Ref. 29) for the oxidation step at high coverage

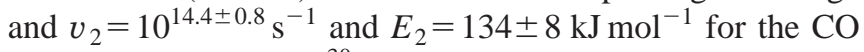
desorption on $\operatorname{Pd}(111) .{ }^{30}$ For the model system used here, we have recently measured $v_{2}=10^{14.9 \pm 0.9} \mathrm{~s}^{-1}$ and $E_{2}=136$ $\pm 9 \mathrm{~kJ} \mathrm{~mol}^{-1}$ for the CO desorption (see Sec. III A) and $v_{4}$ $=10^{7.0 \pm 1.0} \mathrm{~s}^{-1}$ and $E_{4}=62 \pm 8 \mathrm{~kJ} / \mathrm{mol}$ at low reaction temperatures and high oxygen and moderate $\mathrm{CO}$ coverages. ${ }^{36,40}$

Numerical integration of Eqs. (7) and (8) allows us to derive the temporal evolution of $\mathrm{CO}$ and $\mathrm{O}$ coverages. The $\mathrm{CO}_{2}$ production rate is then given by

$$
r_{\mathrm{CO}_{2}}=k_{4} \theta_{\mathrm{CO}} \theta_{\mathrm{O}}
$$

Results of such calculations for typical reaction conditions $\left(T_{\text {sample }}=440 \mathrm{~K}, p_{\text {total }}=1.0 \times 10^{-6}\right.$ mbar $)$ are plotted in Figs. 11 and 12 . As an example, we display the two principle types of transients, i.e., under oxygen-rich conditions (Fig. 11, lower trace, $x_{\mathrm{CO}}=0.2$, transient type 1) and under CO-rich conditions (Fig. 11, upper trace, $x_{\mathrm{CO}}=0.5$, transient type 2). The additional traces in Fig. 11 represent the $\mathrm{CO}$ and $\mathrm{O}$ coverages. A comparison with the experimental data in Figs. 3,5 , and 13 shows that the main features of the shape of the experimental reaction rate curve are well reproduced. In particular, the initial $\mathrm{CO}_{2}$ peak (after $\mathrm{CO}$ beam switch-on) and the second $\mathrm{CO}_{2}$ peak (after $\mathrm{CO}$ beam switch-off) under $\mathrm{CO}$ rich conditions are well described in a semiquantitative manner. A close comparison with the transient in Fig. 13 recorded under roughly the same conditions (second curve

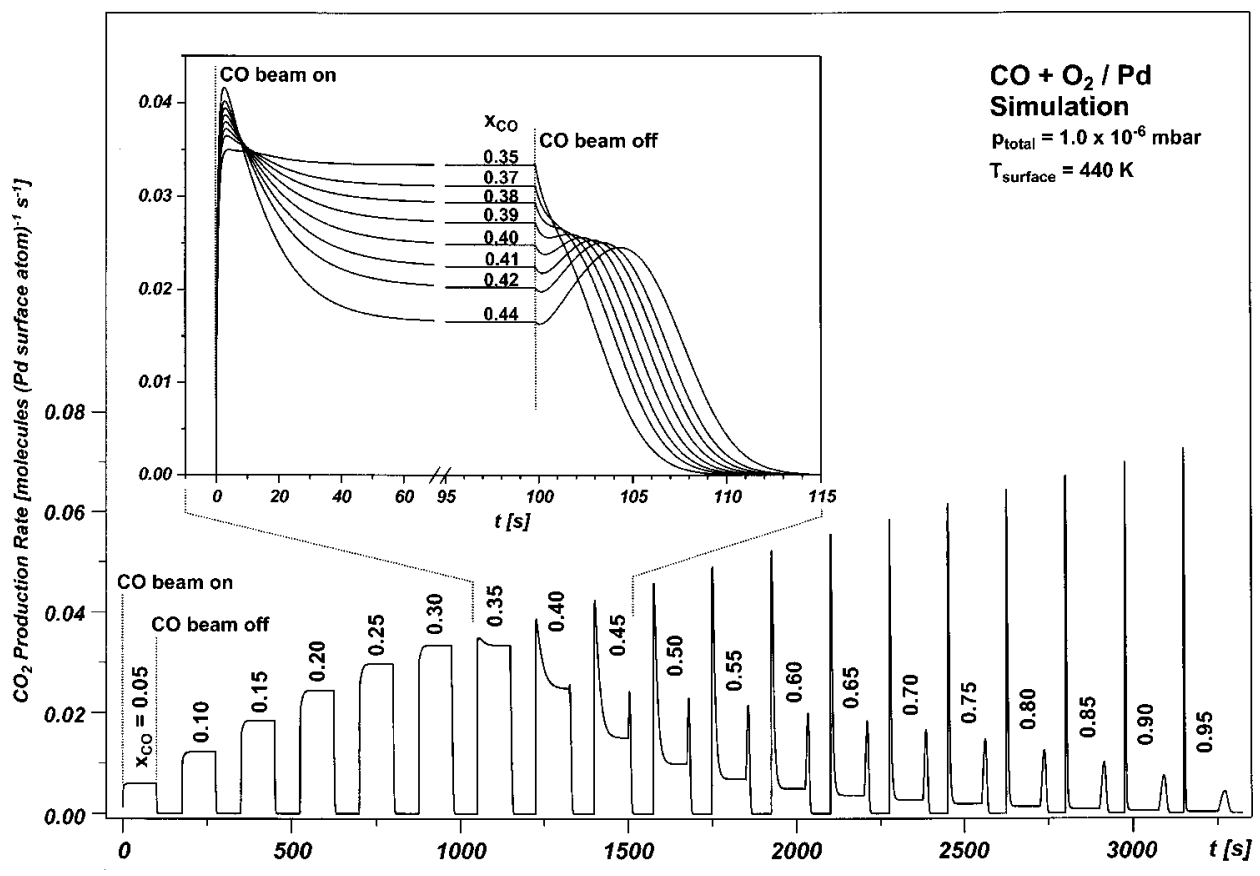

FIG. 12. Simulated transient behavior of the $\mathrm{CO}_{2}$ production rate as a function of the $\mathrm{CO}$ fraction in the impinging gas flux $x_{\mathrm{CO}}\left(T_{\text {Sample }}=440 \mathrm{~K}\right.$, $p_{\text {total }}=1.0 \times 10^{-6} \mathrm{mbar}$ ). The inset shows the transient behavior in the transition region between the oxygen rich and the $\mathrm{CO}$ rich reaction regime. 


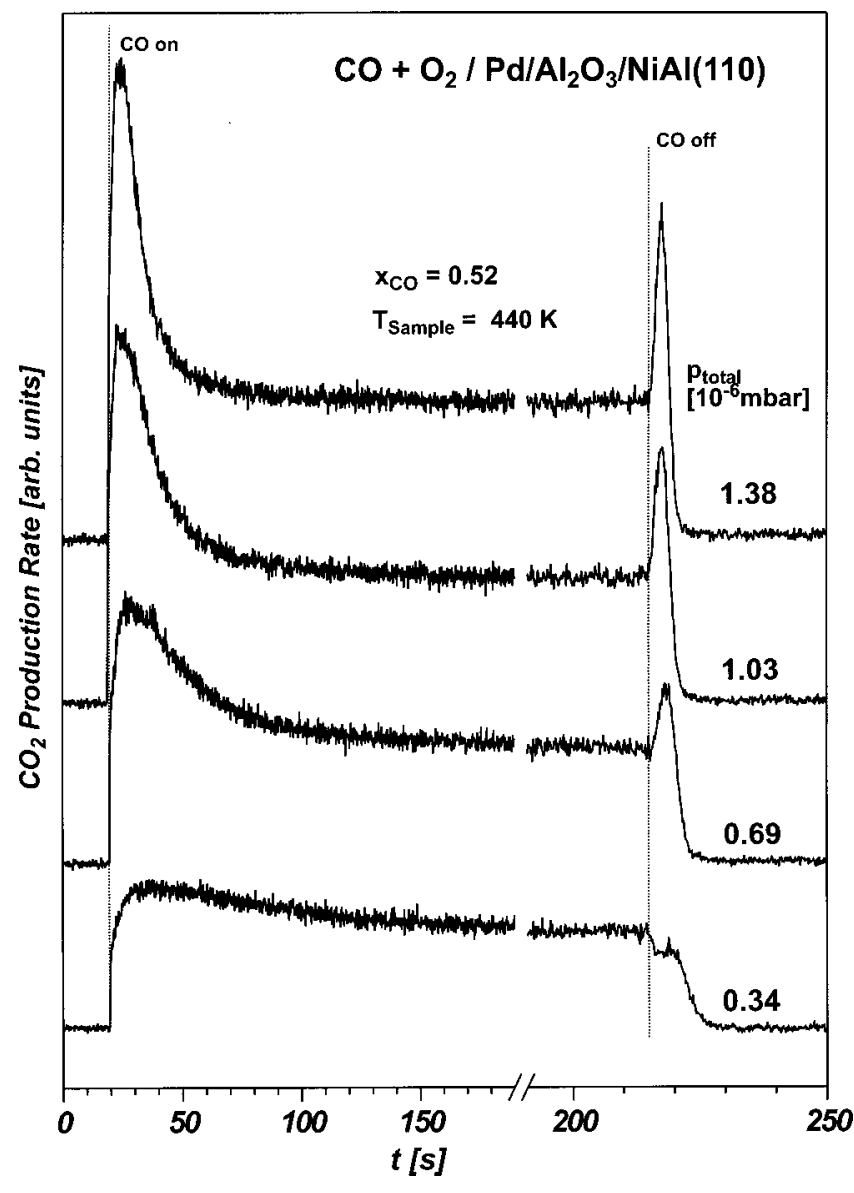

FIG. 13. Transient behavior of the $\mathrm{CO}_{2}$ production rate as a function of the effective total pressure $p_{\text {total }}$, close to the transition between the two reaction regimes $\left(T_{\text {Sample }}=415 \mathrm{~K}\right)$.

from top, $\quad T_{\text {Sample }}=440 \mathrm{~K}, \quad p_{\text {total }}=1.03 \times 10^{-6} \mathrm{mbar}, \quad x_{\mathrm{CO}}$ $=0.52$ ) reveals slight deviations with respect to the shape and the width of both peaks.

In general, these deviations can be considered to be a consequence of the simplistic kinetic model: (a) The exact coverage dependence of both the $\mathrm{CO}$ and $\mathrm{O}_{2}$ sticking coefficients is not taken into account, e.g., the complex influence of precursor states of Ref. 43, (b) the coverage-dependency of energy barriers is not considered, and (c) any influence of the microscopic arrangement of the adsorbates (islanding, etc.) is completely neglected (see, e.g., Ref. 64). Additionally, we disregard all heterogeneity effects, which may exist on the supported model catalyst. Again, it must be underlined that our purpose is not to fit the experimental data, but to explore to what extend the kinetics can be qualitatively explained by a simple homogeneous surface model. It has to be pointed out that considering the present lack of detailed and quantitative information on the reaction system, any further fit of the many parameter system, in particular introducing more complex adsorption and reaction kinetics, does not appear reasonable.

From the transient behavior of the calculated coverages of $\mathrm{CO}$ and oxygen (Fig. 11), the first $\mathrm{CO}_{2}$ peak is easily explained by the fact that, in the considered excess- $\mathrm{CO}$ regime (at steady state), the initially higher oxygen coverage and lower $\mathrm{CO}$ coverage (as compared to the steady state) are favorable for the reaction. The same phenomenon can explain the second $\mathrm{CO}_{2}$ peak: when the $\mathrm{CO}$ beam is closed, $\mathrm{CO}$ depletion occurs due to reaction or desorption. Subsequently, the adsorption rate of $\mathrm{O}_{2}$ molecules increases, which results in a transient maximum of the $\mathrm{CO}_{2}$ production. When no more $\mathrm{CO}$ is adsorbed, the $\mathrm{CO}_{2}$ peak vanishes. This peak can only be observed in the $\mathrm{CO}$-rich regime, where the dissociative chemisorption of $\mathrm{O}_{2}$ is inhibited by chemisorbed $\mathrm{CO}$.

In Fig. 12, a simulated series of $\mathrm{CO}_{2}$ transients is shown, for the same reaction conditions as the ones used in the experiment of Fig. $5\left(T_{\text {Sample }}=440 \mathrm{~K}, p_{\text {total }}=1.0 \times 10^{-6} \mathrm{mbar}\right)$. Considering the simplicity of the model, the agreement between the experiment and the simulation is surprisingly good. The oxygen-rich regime (corresponding to the absence of any $\mathrm{CO}_{2}$ peak during the experiment, i.e., to transients of type 1, see Fig. 3) is present until $x_{\mathrm{CO}} \approx 0.35$. The CO-rich regime (corresponding to the presence of a $\mathrm{CO}_{2}$ peak during the closed-beam period, i.e., to transients of type 2) is reached from $x_{\mathrm{CO}} \geqslant 0.45$.

In the inset in Fig. 12 we consider the transient behavior in the transition region between the oxygen-rich and the $\mathrm{CO}$ rich regime in detail. It is noteworthy that upon termination of the $\mathrm{CO}$ beam, a behavior is found which is qualitatively similar to the effect discussed in the previous section. Over a small regime of $x_{\mathrm{CO}}$ values between 0.39 and 0.44 we find a sudden decrease of the $\mathrm{CO}_{2}$ production followed by a peak in the $\mathrm{CO}_{2}$ production. This subtle effect is a consequence of the competition between two contributions: On the one hand, the reaction rate immediately decreases due to the decreasing $\mathrm{CO}$ coverage upon termination of the beam. On the other hand, the oxygen adsorption rate increases due to the decreasing CO coverage. Due to the different kinetics of both processes, the product of the coverages might reach a maximum, giving rise to the $\mathrm{CO}_{2}$ peak at later time. Although the transient behavior is qualitatively reproduced, some discrepancies remain, comparing the simulation in Fig. 12 with the experimental results shown in Fig. 9. In general, the $\mathrm{CO}_{2}$ production dip in the simulations appears less pronounced than in the experiment. Similar to the discussion above, the discrepancy may be partially related to the simplifications of the kinetic model. Additionally, the influence of the system heterogeneity may result in an enhancement of this kinetic effect. This will be discussed in detail in Sec. III H.

Finally, we have simulated the experiments of Fig. 6, concerning the steady-state reaction rate at various flux ratios and sample temperatures (for $p_{\text {total }}=1.0 \times 10^{-6} \mathrm{mbar}$ ). As seen in Fig. 14, the result of such a simulation is again qualitatively satisfying. The general shapes of the curves, the almost linear increase in the high oxygen coverage region, and the position of the maximum as a function of the surface temperature are rather well reproduced. The main difference is related to the high CO-flux side. Whereas the inhibiting effect of $\mathrm{CO}$ is reasonably well described for a surface temperature of $440 \mathrm{~K}$, the inhibition is overestimated for lower surface temperatures and underestimated for higher temperatures. To a great extent, this is a consequence of the fact that the current model disregards coverage dependencies of the $\mathrm{CO}$ adsorption energy and thus overestimates the CO desorption rate at high temperature and underestimates desorption 


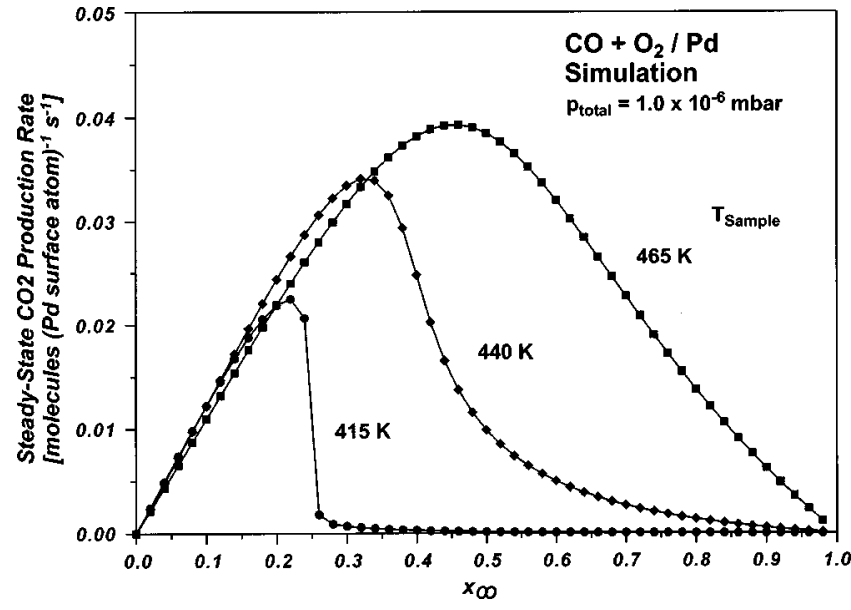

FIG. 14. Simulated steady-state $\mathrm{CO}_{2}$ production rate as a function of the $\mathrm{CO}$ fraction in the impinging gas flux $x_{\mathrm{CO}}\left(p_{\text {total }}=1.0 \times 10^{6} \mathrm{mbar}\right)$.

at low temperature. On a supported model catalyst, this effect may be particularly relevant due to the variety of available adsorption sites and thus the wider range of adsorption energies.

In conclusion of this section, simple kinetic calculations, assuming a homogeneous surface, and using only a limited set of parameters issuing from literature data, allow to simulate the experiments with a good semiquantitative agreement. The behavior of the transient and steady-state rates as a function of the gas partial pressures and of the surface temperature is well described. In particular, with regard to the transition region between the oxygen and $\mathrm{CO}$ rich reaction regimes, it is demonstrated that all the features-including the transient $\mathrm{CO}_{2}$ production peak-are semiquantitatively reproduced by the homogeneous surface model.

A more quantitative agreement would require a refinement of the simulations, e.g., (a) keeping the "mean-field" approach, to improve the model, by using, e.g., coveragedependent energy barriers for the $\mathrm{CO}$ desorption and the $\mathrm{CO}+\mathrm{O}$ elementary reaction and more realistic sticking coefficients of $\mathrm{CO}$ and $\mathrm{O}_{2}$, or (b) using a more local approach, to account for the fact that the surface of a supported model catalyst is heterogeneous and that the adsorbates are not equally distributed over the sample surface. As a basis, for such an attempt, a detailed knowledge of the energetics and kinetics of the surface-gas interaction and structural characteristics of the catalytic system is required, which is, however, only partially available at present.

\section{H. Discussion}

In the previous section we have shown that the transient and steady-state kinetics can at least be semiquantitatively understood assuming a simple homogeneous surface. However, certain deviations remain, in particular with respect to the transient $\mathrm{CO}_{2}$ peaks. In this final section we will end with a brief discussion, considering how the transient behavior may be further modified by the heterogeneity of the model system.

In general we have to distinguish between intraparticle heterogeneity (different sites or facets on a particle) and in- terparticle heterogeneity (structural differences between individual particles). In the first case, strong coupling between these sites by surface diffusion has to be taken into account. ${ }^{5}$ In the latter case every metal particle represents a largely isolated reaction system. Due to the weak adsorption of the reactants on the alumina support inter-particle diffusion is strongly suppressed. Yet, individual adsorption and the reaction rates on the individual particles may differ considerably, e.g., due to differences in particle size, shape or structure. As a consequence, different steady-state coverages may coexist under given conditions on the individual particles. This effect will be particularly important close to the transition region between the two reaction regimes, where the surface coverages sensitively depend on the reaction parameters. Finally, the total macroscopic reaction rate will be a superposition of the individual particle rates, i.e., a superposition of transients ranging from type 1 (oxygen rich, Fig. 3) to type 2 (CO rich, Fig. 3). As a consequence, we expect that in agreement with the experimental data the characteristic transient $\mathrm{CO}_{2}$ production in the transition region will occur over a wider range of $\mathrm{CO}$ fluxes $x_{\mathrm{CO}}$ and may appear more pronounced.

On a microscopic level, there are several pathways via which the heterogeneity of the system may have an influence on the adsorption and reaction rates:

(a) Variations of the local effective pressure: At low reaction temperatures a large fraction of the adsorbing reactants is captured via trapping on the support and diffusion to the metal particles. This "capture zone", effect has been early discussed by Gillet et al. ${ }^{65}$ and Henry et al. ${ }^{66}$ It has been quantitatively investigated in several studies (see, e.g., Refs. 34, 38, 67, 68), recently also on the model system used in this work. ${ }^{69}$ This new adsorption channel gives rise to the effect that the reactant flux per Pd surface atom depends on both the particle size and its surrounding. Due to overlapping of the capture zones, on a particle in close proximity to other particles the effective local pressure will be significantly lower than on an isolated particle. This effect is schematically illustrated in Fig. 15. Experimentally, the effect of the total effective pressure $p_{\text {eff }}$ at constant $x_{\mathrm{CO}}$ is demonstrated in Fig. 13. With increasing total pressure the transient behavior changes in a way similar to what is found for an increasing CO flux fraction at constant total pressure, i.e., with increasing pressure the transition region in a reactivity diagram shifts towards lower CO flux fraction.

(b) Variations in the sticking coefficient due to variations in the surface and defect structure.

(c) Variations in the desorption rate on different adsorption sites (facets, edges, defects).

(d) Variations in the reaction rate: Every particle represents an ensemble of active sites with locally varying activation barriers. Thus the total reaction rate on the particle depends on the ensemble of individual reaction sites.

It remains the question in how far these contributions can be included in further microkinetic simulations to finally 


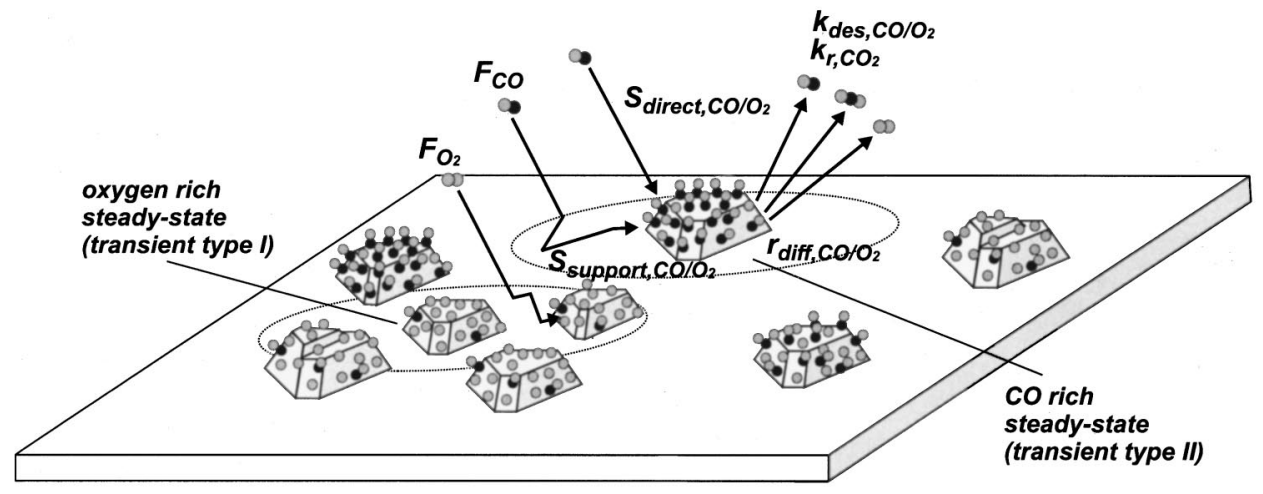

FIG. 15. Schematic representation of the surface coverages close to the transition region between the oxygen-rich and the CO-region. Depending on their structure and surrounding, some particles may remain in the oxygenrich state, whereas others switch to the high $\mathrm{CO}$ coverage region. yield a more complete picture of the reaction kinetics on the model system. On complex catalytic surfaces, on which naturally a certain degree of heterogeneity exists, such simulations will finally be necessary in order to identify and quantify the kinetic effects under discussion. As a basis, such simulations, however, require a detailed knowledge of the energetic and structural properties of the model systems. Here, the available data is still rather limited. Whereas some detailed and representative structural information is available from STM and TEM (transmission electron microscopy), the data basis on gas-surface interaction and surface adsorption/ reactions is largely restricted to single-component systems and to ideal single crystal surfaces. Starting from these simple cases, studies on supported model catalysts with a reduced and controllable level of complexity may provide way to address these questions.

\section{CONCLUSIONS}

In conclusion, we have applied a combined molecular beam/in situ IR reflection absorption spectroscopy approach to study the kinetics of the $\mathrm{CO}$ oxidation reaction under steady state and transient conditions. We employ a supported $\mathrm{Pd}$ model catalyst, based on an ordered $\mathrm{Al}_{2} \mathrm{O}_{3}$ film grown on $\mathrm{NiAl}(110)$. Previously, this systems has been characterized with respect to its structural and adsorption properties. The surface of the Pd islands is to a large extend dominated by (111)-facets. The particles are characterized by an average size of $5.5 \mathrm{~nm}$ and an island density of $10^{12} \mathrm{~cm}^{-2}$.

In the temperature range $(415-465 \mathrm{~K})$ and pressure range ( $\leqslant 10^{-6}$ mbar) investigated, we find no indications for a significant deactivation of the model catalyst on the time scale of the experiment $\left(\sim 10^{3} \mathrm{~s}\right)$.

(ii) The steady-state reaction rate was systematically determined as a function of the $\mathrm{CO}$ flux fraction and the surface temperature. The different reaction regimes are discussed.

(iii) We have employed in situ IRA spectroscopy to follow changes in the occupation of adsorption sites under reaction conditions. Starting from O-rich reaction conditions, the linear increase in $\mathrm{CO}$ coverage with the CO flux is accompanied by a increased occupation of bridge sites versus hollow sites, which are predominantly occupied at low CO coverage. The vibrational frequencies are shifted due to the influence of coadsorbed oxygen. In the transition region to the $\mathrm{CO}$-rich regime, the sudden increase in the $\mathrm{CO}$ coverage is due to a strongly increased occupation of bridge sites. Additionally, in the high CO-flux region, a small fraction of on-top sites is occupied which may tentatively be assigned to defects.

(iv) We have systematically investigated the transient behavior of the system under conditions of continuous $\mathrm{O}_{2}$ flux and modulated $\mathrm{CO}$ flux. The different types of transients are discussed. In particular we have investigated the appearance of a transient $\mathrm{CO}_{2}$ peak after switching off the $\mathrm{CO}$ beam. Using time-resolved IR absorption spectroscopy we demonstrate that the observed transient behavior close to the transition region-at least for the model system used in this study - is not related to defect sites, as was proposed previously. Instead we suggest complementary explanations, which are related to (a) the $\mathrm{CO}$ induced inhibition of $\mathrm{O}_{2}$ adsorption and (b) the intrinsic heterogeneity of the model system allowing coexistence of different steady states.

(v) With a simple kinetic model based on the LangmuirHinshelwood mechanism and on previous experimental data available on $\operatorname{Pd}(111)$ and on the $\mathrm{Pd}$ model system used here, we show that a large part of the reaction kinetics can be understood by considering a homogeneous surface. The good semiquantitative agreement between experiments and simulations is obtained over the range of flux and temperature conditions covered in this study. A close investigation of the $\mathrm{CO}_{2}$ production after closing of the $\mathrm{CO}$ beam suggests, that the transient behavior can be largely explained by these simulations, taking into account the interplay between $\mathrm{CO}$ desorption/reaction and the inhibition of $\mathrm{O}_{2}$ adsorption by $\mathrm{CO}$. Additionally, the effect is expected to be enhanced by the surface heterogeneity of the supported cluster system leading to coexistence of a multitude of differing steady states under given reaction conditions.

\section{ACKNOWLEDGMENTS}

This project has been funded by the Max-Planck-Society and the Deutsche Forschungsgemeinschaft. We are particularly grateful to O. Frank whose work related to solution of numerous technical difficulties with respect to the molecular 
beam system was extremely valuable. We would like to thank the service groups for mechanics and electronics at the FHI which have been substantially involved in the realization of the molecular beam project. H.-J. F. is grateful for his support from CNRS as chercheur associé at CRMC2-CNRS in Luminy.

${ }^{1}$ M. G. Mason, Phys. Rev. B 27, 748 (1983).

${ }^{2}$ G. K. Wertheim, Z. Phys. D: At., Mol. Clusters 12, 319 (1989).

${ }^{3}$ C. R. Henry, C. Chapon, C. Goyhenex, and R. Monot, Surf. Sci. 272, 283 (1992).

${ }^{4}$ C. R. Henry, Surf. Sci. Rep. 31, 231 (1998).

${ }^{5}$ V. P. Zhdanov and B. Kasemo, Surf. Sci. Rep. 39, 25 (2000).

${ }^{6}$ V. P. Zhdanov and B. Kasemo, Surf. Sci. 405, 27 (1998).

${ }^{7}$ V. P. Zhdanov and B. Kasemo, J. Catal. 170, 377 (1997).

${ }^{8}$ K. Hayek, R. Kramer, and Z. Paál, Appl. Catal., A 162, 1 (1997).

${ }^{9}$ S. Ogawa and S. Ichikawa, Phys. Rev. B 51, 17231 (1995).

${ }^{10}$ G. Rupprechter, G. Seeber, H. Goller, and K. Hayek, J. Catal. 186, 201 (1999).

${ }^{11}$ G. Pacchioni and N. Rösch, Surf. Sci. 306, 169 (1994).

${ }^{12}$ G. M. Pajonk, in Handbook of Heterogeneous Catalysis, edited by G. Ertl, H. Knözinger, and J. Weitkamp (VCH, Weinheim, 1997), Vol. 3.

${ }^{13}$ W. C. Conner and J. L. Falconer, Chem. Rev. 95, 759 (1995).

${ }^{14}$ D. W. Goodman, Surf. Rev. Lett. 2, 9 (1995).

${ }^{15}$ H.-J. Freund, M. Bäumer, and H. Kuhlenbeck, Adv. Catal. 45, 333 (2000).

${ }^{16}$ M. Bäumer, J. Libuda, A. Sandell et al., Ber. Bunsenges. Phys. Chem. 99, 1381 (1995).

${ }^{17}$ M. Bäumer, J. Libuda, and H.-J. Freund, in Chemisorption and Reactivity on Supported Clusters and Thin Films, edited by M. Lambert and G. Pacchioni (Kluwer Academic, New York, 1997), p. 61.

${ }^{18}$ D. R. Rainer and D. W. Goodman, J. Mol. Catal. A: Chem. 131, 259 (1998).

${ }^{19}$ H.-J. Freund, Angew. Chem. Int. Ed. Engl. 36, 452 (1997).

${ }^{20}$ R. M. Jaeger, H. Kuhlenbeck, H.-J. Freund et al., Surf. Sci. 259, 235 (1991).

${ }^{21}$ J. Libuda, F. Winkelmann, M. Bäumer et al., Surf. Sci. 318, 61 (1994).

${ }^{22}$ M. Bäumer and H.-J. Freund, Prog. Surf. Sci. 61, 127 (1999).

${ }^{23}$ K. Wolter, O. Seiferth, H. Kuhlenbeck et al., Surf. Sci. 399, 190 (1998).

${ }^{24}$ K. H. Hansen, T. Worren, S. Stempel et al., Phys. Rev. Lett. 83, 4120 (1999).

${ }^{25}$ M. Asscher and G. A. Somorjai, in Atomic and Molecular Beam Methods, edited by G. Scoles (Oxford University Press, Oxford, 1988), Vol. 2, p. 489.

${ }^{26}$ M. P. D’Evelyn and R. J. Madix, Surf. Sci. Rep. 3, 413 (1984).

${ }^{27}$ C. T. Rettner, D. J. Auerbach, J. C. Tully, and A. W. Kleyn, J. Phys. Chem. 100, 13021 (1996).

${ }^{28}$ J. A. Barker and D. J. Auerbach, Surf. Sci. Rep. 4, 1 (1985).

${ }^{29}$ T. Engel and G. Ertl, J. Chem. Phys. 69, 1267 (1978).

${ }^{30}$ T. Engel, J. Chem. Phys. 69, 373 (1978).

${ }^{31}$ C. T. Campbell, G. Ertl, H. Kuipers, and J. Segner, J. Chem. Phys. 73, $5862(1980)$
${ }^{32}$ L. S. Brown and S. J. Sibener, J. Chem. Phys. 90, 2807 (1989).

${ }^{33}$ L. S. Brown and S. J. Sibener, J. Chem. Phys. 89, 1163 (1988).

${ }^{34}$ I. Stará, V. Nehasil, and V. Matolín, Surf. Sci. 365, 69 (1996).

${ }^{35}$ I. Stará, V. Nehasil, and V. Matolín, Surf. Sci. 331-333, 173 (1995).

${ }^{36}$ I. Meusel, J. Hoffmann, J. Hartmann et al., Catal. Lett. (submitted).

${ }^{37}$ C. Becker and C. R. Henry, Catal. Lett. 43, 55 (1997).

${ }^{38}$ C. Becker and C. R. Henry, Surf. Sci. 352, 457 (1996).

${ }^{39}$ J. Libuda, I. Meusel, J. Hartmann, and H.-J. Freund, Rev. Sci. Instrum. 71, 4395 (2000).

${ }^{40}$ I. Meusel, M. Heemeier, B. Richter et al. (in preparation).

${ }^{41}$ J. Hoffmann, I. Meusel, J. Hartmann et al. (in preparation).

${ }^{42}$ L. Piccolo, Ph.D. thesis, Marseille, 1999.

${ }^{43}$ L. Piccolo, C. Becker, and C. R. Henry, Appl. Surf. Sci. 164, 156 (2000).

${ }^{44} \mathrm{~T}$. Engel and G. Ertl, in The Chemical Physics of Solid Surfaces and Heterogeneous Catalysis, edited by D. A. King and D. P. Woodruff (Elsevier, New York, 1982), Vol. 4, p. 73.

${ }^{45}$ H. Graoui, S. Giorgio, and C. R. Henry, Surf. Sci. 417, 350 (1998).

${ }^{46}$ V. Matolín, E. Gillet, and N. Kruse, Surf. Sci. 186, L541 (1987).

${ }^{47}$ A. Hammoudeh, Ph.D. thesis, Berlin, 1994.

${ }^{48}$ A. Ortega, F. M. Hoffman, and A. M. Bradshaw, Surf. Sci. 119, 79 (1982).

${ }^{49}$ A. M. Bradshaw and F. M. Hoffman, Surf. Sci. 72, 513 (1978).

${ }^{50}$ J. C. Cook, S. K. Clowes, and E. M. McCash, J. Chem. Soc., Faraday Trans. 93, 2315 (1997).

${ }^{51}$ M. Tüshaus, W. Berndt, H. Conrad et al., Appl. Phys. A: Solids Surf. 51, 91 (1990).

${ }^{52}$ M. Tüshaus, Ph.D. thesis, Berlin, 1990.

${ }^{53}$ B. Bourguignon, S. Carrez, B. Dragnea, and H. Dubost, Surf. Sci. 418, 171 (1998).

${ }^{54}$ R. Raval, S. Haq, M. A. Harrison et al., Chem. Phys. Lett. 167, 391 (1990).

${ }^{55}$ R. Raval, S. Haq, G. Blyholder, and D. A. King, J. Electron Spectrosc. Relat. Phenom. 54-55, 629 (1990).

${ }^{56}$ H. Pfnür, D. Menzel, F. M. Hoffmann et al., Surf. Sci. 93, 431 (1980).

${ }^{57}$ L.-W. H. Leung, J. W. He, and D. W. Goodman, J. Chem. Phys. 93, 8328 (1990).

${ }^{58}$ A. M. deJong and J. W. Niemantsverdriet, J. Chem. Phys. 101, 10126 (1994).

${ }^{59}$ F. M. Hoffmann, Surf. Sci. Rep. 3, 107 (1983).

${ }^{60}$ L. Piccolo, C. Becker, and C. R. Henry, Eur. Phys. J. D 9, 415 (1999).

${ }^{61}$ C. R. Henry, C. Chapon, and C. Duriez, Z. Phys. D: At., Mol. Clusters 19, 347 (1991).

${ }^{62}$ H. Conrad, G. Ertl, and J. Küppers, Surf. Sci. 76, 323 (1978).

${ }^{63}$ M. Eriksson and L.-G. Ekedahl, Surf. Sci. 412/413, 430 (1998).

${ }^{64}$ J. Wintterlin, S. Völkening, T. V. W. Janssens et al., Science 278, 1931 (1997).

${ }^{65}$ E. Gillet, S. Channakhone, V. Matolin, and M. Gillet, Surf. Sci. 152/153, 603 (1985).

${ }^{66}$ C. R. Henry and C. Chapon, Surf. Sci. 156, 952 (1985).

${ }^{67}$ F. Rumpf, H. Poppa, and M. Boudart, Langmuir 4, 723 (1988).

${ }^{68}$ C. R. Henry, C. Chapon, and C. Duriez, J. Chem. Phys. 95, 804 (1991)

${ }^{69}$ T. Dellwig, J. Hartmann, J. Libuda et al., J. Mol. Catal. (in press). 